\title{
Unmanned Aircraft Systems Performance in a Climate-Controlled Laboratory
}

\author{
Matteo Scanavino ${ }^{1}$ (D) Arrigo Avi $^{2} \cdot$ Andrea Vilardi $^{2} \cdot$ Giorgio Guglieri $^{1}$
}

Received: 23 September 2020 / Accepted: 1 April 2021 / Published online: 27 April 2021

(C) The Author(s) 2021

\begin{abstract}
Despite many research studies focus on strategies to improve autopilot capabilities and bring artificial intelligence onboard Unmanned Aircraft Systems (UAS), there are still few experimental activities related to these vehicle performance under unconventional weather conditions. Air temperature and altitudes directly affect thrust and power coefficients of small scale propeller for UAS applications. Reynolds numbers are usually within the range 10,000 to 100,000 and important aerodynamic effects, such as the laminar separation bubbles, occur with a negative impact on propulsion performance. The development of autonomous UAS platforms to reduce pilot work-load and allow Beyond Visual Line of Sight (BVLOS) operations requires experimental data to validate capabilities of these innovative vehicles. High quality data are needed for a deep understanding of limitations and opportunities of UAS under unconventional flight conditions. The primary objective of this article is to present the characterization of a propeller and a quadrotor capabilities in a pressure-climate-controlled chamber. Mechanical and electrical data are measured with a dedicated test setup over a wide range of temperatures and altitudes. Test results are presented in terms of thrust and power coefficient trends. The experimental data shows low Reynolds numbers are responsible for degraded thrust performance. Moreover, details on brushless motor capabilities are also discussed considering different temperature and pressure conditions. The experimental data collected in the test campaign will be leveraged to improve UAS design, propulsion system modelling as well as to provide guidelines for safe UAS operations in extreme environments.
\end{abstract}

Keywords UAS performance $\cdot$ UAS testbed $\cdot$ Harsh environmental conditions

\section{Introduction}

In the last few years, Unmanned Aircraft Systems (UAS) have been widely involved in recreational and civil applications. This has been possible thanks to the integration of innovative sensors and the development of advanced flight modes. Today, many efforts are spent to provide Artificial Intelligence (AI) on-board UAS to reduce pilot intervention and enable autonomous operations. Optimal path planning [1], collision avoidance $[13,26]$ as well

Matteo Scanavino

matteo.scanavino@polito.it

1 Department of Mechanical and Aerospace Engineering, Politecnico di Torino, Corso Duca degli Abruzzi 24, 10129 Torino, Italy

2 terraXcube, Eurac Research, Via Ipazia 2, 39100 Bolzano, Italy as swarm management and coordination [37] are just few example of emerging topics strongly related to AI.

Considering harsh environments or dangerous applications, UAS (and more in general autonomous vehicles) have potential to support human activities to accomplish mission objectives, such as search and rescue in earthquakes, avalanches, floods and even space exploration. Among all the types of UAS, multirotor platforms are promising solutions thanks to their high flexibility, low cost and relatively simple control architecture. To fully exploit their capabilities, the scientific community is involved in improvement of Guidance Control and Navigation (GNC) algorithms as well as optimization of vehicle performance.

In the last few years, many research institutes have deeply investigate multirotor UAS from an experimental point of view. In 2016 the Aeromechanics Office at NASA Ames Research Center carried out a test program on commercial and hobbyist level multicopter to collect a set of high 
quality data of their performance [27]. To this end, five UAS commonly leveraged for photographic surveillance were investigated in the U.S. Army 7-by-10 wind tunnel at NASA Ames. Performance data including mechanical quantities (thrust, torque and motor speed) and electrical data (voltage and current) were collected for each vehicle considering different combinations of wind tunnel flow speeds, throttle level and UAS attitude. A similar approach was adopted by the California Polytechnic State University [6] where wind tunnel tests on a DJI Phantom were performed in 2018. The author of this study has highlighted that the experimental measurements exhibit the same trends as for NASA Ames tests; however, significant difference in magnitude have been experienced in aerodynamic forces and power measurements probably due to aerodynamic interference as a consequence of smallest wind tunnel test section at California Polytechnic State University compared to NASA Ames facility.

The main limitation of the aforementioned studies is they consider multicopters mounted in custom test stands so that only hover flight conditions are investigated. To this end, in 2019 NASA Langley Research Center [12] leveraged a vertical wind tunnel to evaluate the dynamic response of small commercial multirotor UAS. Free flight conditions were simulated in the 12-foot Low Speed Tunnel as well as in the 20-foot Vertical Speed Tunnel designing a tethered system to prevent damages in case of loss of control or during failure analysis. The test campaign allowed to acquire data on multirotor capabilities in descend flights and vehicle flying qualities in terms of pilot work load. As the vortex ring state conditions were reached, the overall pilot work load reached the highest value. Off-nominal flight conditions, such as rotor failures, were safely explored: windmill conditions were experienced suggesting this is an important aerodynamic effect when modelling failures.

Other experimental studies investigate multicopter performance in indoor environments from an aerodynamic point of view. Ground, ceiling and near wall effects are responsible for complex flow fields resulting in non-linear behaviours. Ground effect is a well known phenomenon in helicopter literature consisting in thrust increment when the vehicle is close to ground. A comprehensive analysis of these effects was carried out by Conyers at the University of Denver [5] considering small scale quadrotors. The experimental investigation performed by the author shows the assumptions made by Cheeseman and Bennet [4] theory for helicopter ground effect estimation is not valid when considering multicopter UAS due to the complexity of the aerodynamic fields arising by the interaction of multiple rotating blades. In his studies, Conyers designed and developed a custom test stand to measure isolated propeller and full vehicle performance considering different rotor mutual displacement and distance to ground, ceiling and wall.

Considering harsh environments, such as low temperature and high altitudes, few experimental data on small UAS performance are available. Ice accretion on propeller is the major topic related to UAS performance at low temperature and is widely investigated by experimental test performed by Richard Hann [16, 17]. The primary impact of ice is related to changes in the aerodynamic field resulting in poor propeller efficiency and reduced thrust coefficient. Temperature and liquid water content are the driving quantities that lead to different ice conditions (rime, glaze or mixed) resulting in unpredictable performance.

While ice directly affects airfoil shape, propeller and full vehicle performance (thrust and torque coefficients) are also influenced by the Reynolds number which relay on air temperature and pressure. In the past, Reynold effects on isolated propellers were investigated by Brandt and Selig by means of wind tunnel tests at different flow speed. However, except for our previous work [31] on propeller tests in a climate controlled facility, no other experimental activities investigate temperature and pressure influence at low Reynolds number for propeller and multirotor UAS performance. While in our previous study we highlighted the effect of temperature and pressure on propeller thrust, the primary objective of this article is to integrate the research including additional details on the isolated rotor performance and full vehicle data under unconventional atmospheres. Moreover, the experimental setup is completely revisited to avoid undesired effects related to extreme temperature on sensors. Thrust, torque and power coefficients are reported for a wide range of Reynolds numbers combining temperature and pressure; a detailed investigation of the propulsion system is included to quantify secondary effects such as motor resistance and no load current changes and propeller response to throttle commands. The broader goal of the research is to provide a high quality set of data under unconventional weather conditions for isolated rotor and multicopter UAS to improve design and modelling of these innovative vehicles.

This article is structured as follows. Section 2 describes the experimental setup, sensors, propeller and vehicle used for the tests. Methodology, including simulated temperatures and altitudes as well as test protocols are described in Section 3. Data reduction is discussed in Section 4 providing the reference equations for performance assessment. Results are presented in Section 5 including a comparison between isolated rotor and full vehicle performance. Details on brushless motor behaviour are also included. Finally, conclusions and future works are given in Section 6. 


\section{Experimental Setup}

Temperature and pressure effect on aerodynamic performance of a single rotor as well as full vehicle are investigated in terraXcube, Eurac Research. The laboratory allows to simulate extreme environmental conditions in a safe and controllable facility $[25,36]$. The large simulator is a hypobaric climatic chamber where the test engineer can set desired atmospheric conditions from a dedicated control room. While the set-point temperature is directly defined by the test engineer, the desired altitude is converted by the control software of the facility to the corresponding pressure exploiting the barometric equation

$p=p_{0}\left(\frac{T_{0}-K h}{T_{0}}\right)^{5.255}$,

where $p_{0}$ and $T_{0}$ are the standard pressure and temperature (respectively $p_{0}=1013.25 \mathrm{hPa}$ and $T_{0}=288.15 \mathrm{~K}$ ), $h$ is the set-point altitude in meters and $K$ is the standard temperature gradient according to the International Standard Atmosphere (ISA) $-K=0.0065 \mathrm{~K} / \mathrm{m}$.

\subsection{Test Stand}

The test stand consists of a welded-steel construction with a central hollow tube and two removable end caps. The central hollow cylinder, $130 \mathrm{~mm}$ in diameter and $1500 \mathrm{~mm}$ height, is filled with $25 \mathrm{~kg}$ of sand to reduce mechanical vibrations, as reported in [5]. The upper removable end cap is designed to house a 6-axes load cell. The test stand is used for both propeller and full vehicle tests with suitable interface plate as in Fig. 1. To reduce the aerodynamic interaction between the propeller downstream flow and the test stand, the brushless motor base plate for propeller testing is installed $28 \mathrm{~cm}$ away from the load cell sensor to avoid interaction with the test stand cap.

\subsection{Sensors}

Forces and torques $(\mathrm{F} / \mathrm{T})$ measurements are collected using the 30E15A4 sensor by JR3 [20]. The same load cell is involved in the experimental activity described by Russell et al. in [27] for UAS wind tunnel analysis. This F/T device has a capacity of $( \pm 200 N, \pm 200 N, \pm 400 N)$ for thrust $\left(F_{x}, F_{y}, F_{z}\right)$ and $\pm 16 \mathrm{Nm}$ for torques along all axes; note that the $z$-axis is aligned along the sensor vertical direction while $x$ and $y$ are the in-plane $\mathrm{F} / \mathrm{T}$ axes. The minimum resolutions of the sensor are respectively $(0.025 \mathrm{~N}, 0.025 \mathrm{~N}, 0.05 \mathrm{~N})$ for thrust and $0.002 \mathrm{Nm}$ for torques, with a manufacturer-stated accuracy of $0.25 \%$. This sensor includes a dedicated external electronics that allows to select analogue or digital acquisition. During the tests, the load cell is installed inside the test section over the test stand, the JR3 electronics is placed in the control room and directly connected to the acquisition computer. All the measurements are taken in digital mode with a sampling frequency of $10 \mathrm{~Hz}-100 \mathrm{~ms}$.

Calibration is performed before the tests to assess sensor force and moment accuracies at $+25{ }^{\circ} \mathrm{C}$ and $-40{ }^{\circ} \mathrm{C}$ (minimum temperature set in our study). Figure 2 shows thrust and torque calibration measured data. If the
Fig. 1 Test stand inside terraXcube laboratory. a Propeller mounting and tachometer sensor b Quadrotor mounting

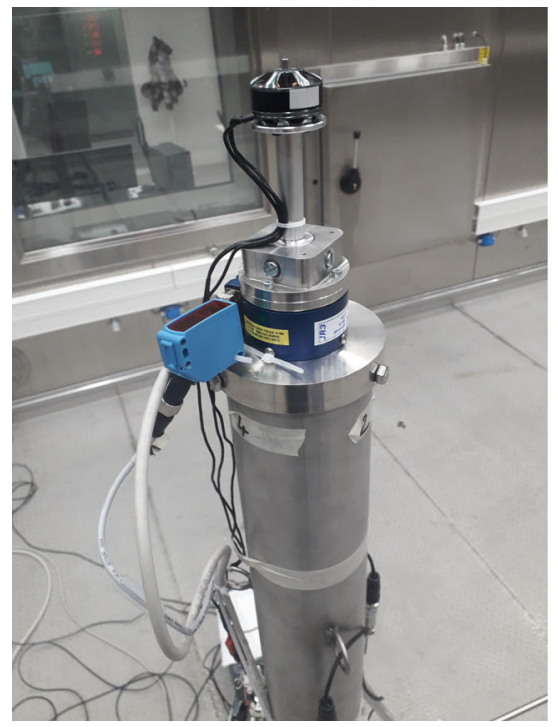

(a)

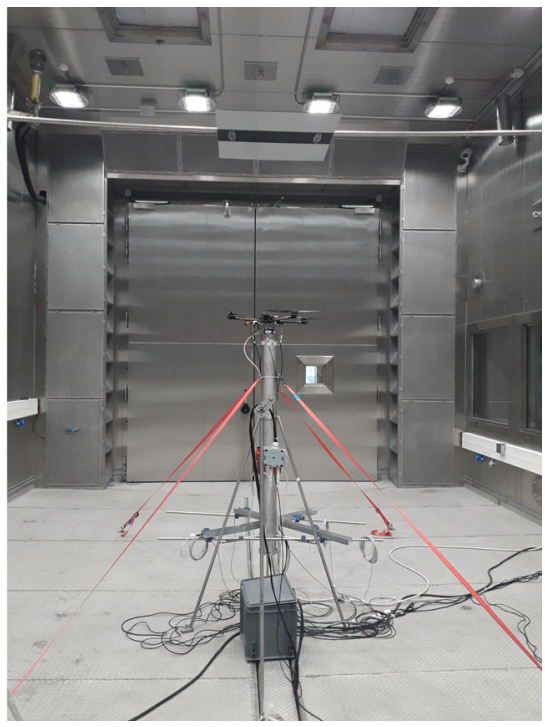

(b) 


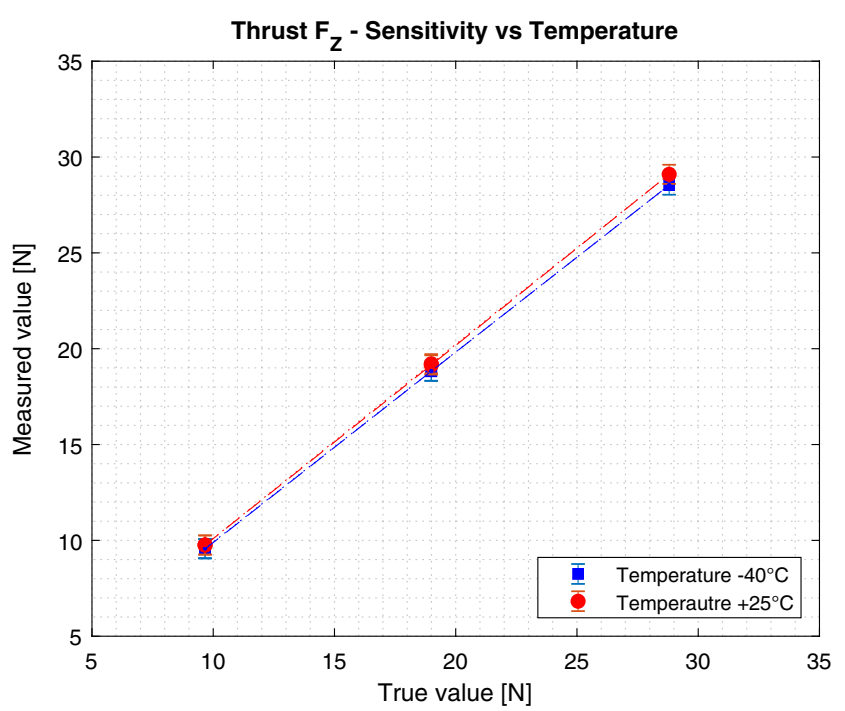

(a)

Fig. 2 Load cell calibration. a Thrust calibration b Torque calibration

load cell measurements were perfect, the measured loads would follow a line with a slope equal to one; the resulting calibration error is close to $\pm 0.01 F_{z}$ for both temperatures. In a similar way, the sensitivity of measured moment compared to true values shows a calibration error close to $\pm 0.03 M_{z}$ proving that the load cell is reliable for both measurements in standard and low temperatures. As reported by [27], the accuracy of this sensor is higher compare to sting balances used in wind tunnel facilities; however, the JR3 F/T device is selected as it represent an acceptable balance between performance and cost. Moreover, the sensor capability to operate at $-40{ }^{\circ} \mathrm{C}$ and the possibility to employ the same F/T sensor as in [27] for data comparison suggest to install this load cell.

Motor speeds are measured using digital photoelectric sensors (Sick WLAP 16 [33]) which sense the Blade Passing Frequency (BPF). Figure 1a show the sensor mounting for propeller test; a reflective square-marker is placed approximately $2 \mathrm{~m}$ over the test bed as shown in Fig. $1 \mathrm{~b}$. In this way, non-intrusive measurements of motor angular rates are possible without any additional probes on propellers. As the photoelectric sensors provide an impulse each time the light beam is interrupted by the blade, the BPF is converted in to motor speed by a dedicated counter module of the data acquisition system (DAQ). The minimum operating temperature of the WALP sensor is $-40{ }^{\circ} \mathrm{C}$ which is compatible with the temperatures expected during test sessions. The sensor frequency of commutation is $1000 \mathrm{~Hz}$, one order of magnitude higher than the maximum expected motor speed (approximately $250 \mathrm{~Hz}$ ).

Finally, the test stand is equipped with shunt resistors [24] to measured the electric current and voltage of each

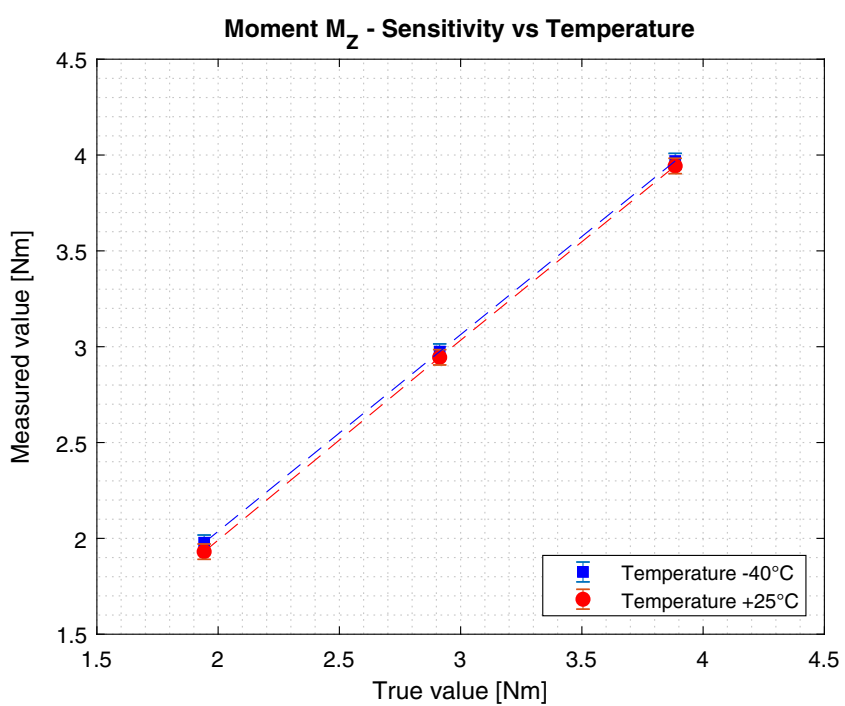

(b)

motor of the UAS. The selected precision shunt resistor is characterized by a resistance of $1 \mathrm{~m} \Omega(50 A$ at $50 \mathrm{mV}$ maximum) with an accuracy of $0.25 \%$. The operating temperature of the sensor is in the range $-40{ }^{\circ} \mathrm{C}$ to $+60{ }^{\circ} \mathrm{C}$ with a Temperature Coefficient of Resistance (TRC) of $\pm 15 \mathrm{ppm} /{ }^{\circ} \mathrm{C}$.

\subsection{Additional Sensors and Data Acquisition System}

The test section of the large chamber of terraXcube simulator is equipped with sensors to measure the environmental parameters of interest and provide feedback signals for atmosphere control. For the purposes of this study, additional sensors have been placed inside the test section, near the test stand, to collect temperature and pressure data. The temperature is measured using the EE211 Eletronik digital sensor [11]. The temperature probe (PT100) maximum accuracy is $\pm 0.5^{\circ} \mathrm{C}$ at $-40{ }^{\circ} \mathrm{C}$ and $\pm 0.1^{\circ} \mathrm{C}$ at room temperature $\left(+20^{\circ} \mathrm{C}\right)$. The test section pressure is recorded with the precision barometer HD9408.3B by Delta OHM [7], with an accuracy of $\pm 0.3 \mathrm{hPa}$ in the range (500 to $1200 \mathrm{hPa}$ ) and $\pm 0.4 \mathrm{hPa}$ in the range ( 0 to $500 \mathrm{hPa}$ ).

Additional equipments include the integrated digital acquisition system Ipetronik [19], a rugged modular system that is able to manage at the same time excitation of the sensors as well as analogue and digital signal readings. The experimental setup encompasses a DC power supply in the control room to provide electrical power to the vehicle or rotor and avoid battery charging time. The supply voltage is controlled and set to $16.8 \mathrm{~V}$, with a maximum output current of 70A. This solution allows to reduce transient voltage fluctuations which are common when using Li-Po 
batteries. As the objective of this study is the aerodynamic performance of UAS at low Reynolds numbers, thermal effect on battery have not been accounted for.

\subsection{Isolated Rotor and Full Vehicle Tested}

The propeller and motor used for the tests are representative of small/medium scale UAS. The T-Motor $15^{\prime} \times 5^{\prime}$ is a carbon fibre propeller (Fig. 3) used for professional drone applications. Even tough nylon propellers are more common for hobbyists and researchers due to their low cost, the TMotor is chosen as it is possible to compare the data with the experimental test performed by Russell et al. [27]. The brushless motor is the T-Motor MN3508 380KV [34] with a maximum power of $310 \mathrm{~W}$. The motor is controlled by a Turnigy Push $30 A$ ESC. The PWM signals to the Electronic Speed Controllers are provided by the test engineer through a transmitter connected to a Radio Control (RC). The same PWM sequence $(50 \%, 66 \%, 83 \%$ and full throttle) are provided to the motor for all the simulated atmospheres.

The quadrotor vehicle used in the tests is a professional UAS (Q4L multicopter in Fig. 4) with a Maximum TakeOff Weight (MTOW) of $1.7 \mathrm{~kg}$ and is designed for crop field monitoring with optical sensors. The four motors and propellers are mounted according the quad-X architecture and are the same used for the single propeller test. The Electronic Speed Controllers installed in the vehicle are the Flyduino KISS ESCs. This vehicle is chosen because of its simple reconfigurable design which allows a friendly interface with the test stand and load cell. Moreover, preliminary experimental studies in wind tunnel for drag coefficient estimate were performed on the same UAS by Mascarello in [22]. As the primary objective of this work is the aerodynamic characterization of the vehicle performance in terms of thrust and power coefficients, the onboard autopilot is bypassed and used only to supply the ESCs with the required voltage. The PWM signals to the ESCs are provided by the test engineer through the onboard transmitter connected to the Radio Control (RC). 50\%, 66\%, $83 \%$ and full throttle are set for each simulated atmosphere.

\section{Test Methodology}

The objective of this study is to measure the performance of the isolated propeller and the full vehicle quadrotor

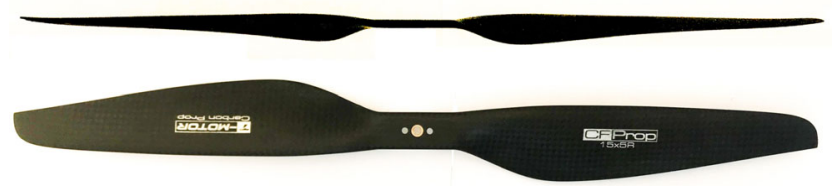

Fig. 3 T-Motor $15^{\prime} \times 5^{\prime}$ propeller-Lateral and frontal view

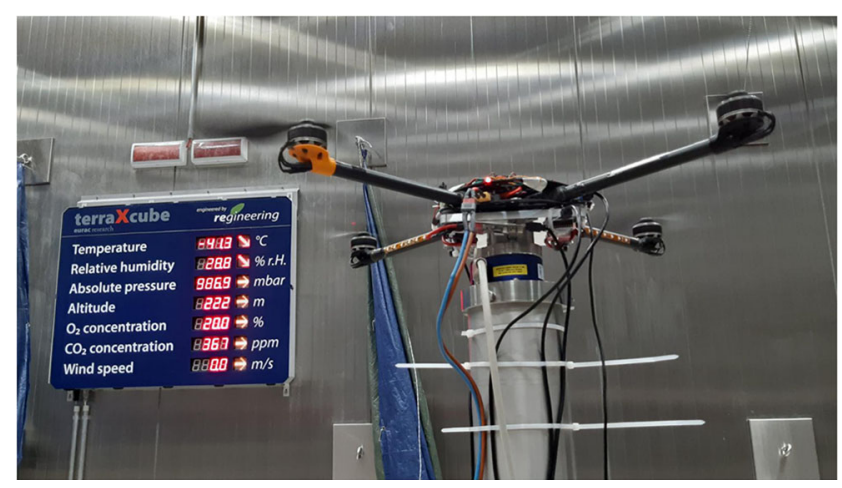

Fig.4 Q4L UAS during full vehicle test

in term of thrust, torque, motor speed and electric power consumption for different atmospheric conditions. The following temperatures are considered: $+40{ }^{\circ} \mathrm{C},+20{ }^{\circ} \mathrm{C}$, $0{ }^{\circ} \mathrm{C},-20{ }^{\circ} \mathrm{C}$ and $-40{ }^{\circ} \mathrm{C}$; for all of these temperatures, the equivalent altitudes set up in the test section are $0 \mathrm{~m}$ (sea level), $1500 \mathrm{~m}, 3000 \mathrm{~m}, 4500 \mathrm{~m}$ and $6000 \mathrm{~m}$. Based on Eq. 1, the corresponding pressure are respectively $1013 \mathrm{hPa}$, $845 \mathrm{hPa}, 700 \mathrm{hPa}, 577 \mathrm{hPa}$ and $470 \mathrm{hPa}$. The test section air densities resulting from the aforementioned combinations of temperature and pressure are computed using the ideal gas law

$p=\rho R T$,

where $p$ is the air pressure $[\mathrm{Pa}], \rho$ is the density $\left[\mathrm{kg} / \mathrm{m}^{3}\right]$, $R$ is the specific gas constant $(287 \mathrm{~J} / \mathrm{kgK}$ for the air) and $T$ is the temperature [K]. Figure 5 shows the air densities corresponding to the environmental conditions. The high densities correspond to low temperature and sea level conditions; the opposite for high temperatures and altitude. In total, 25 different climatic conditions are investigated in this study.

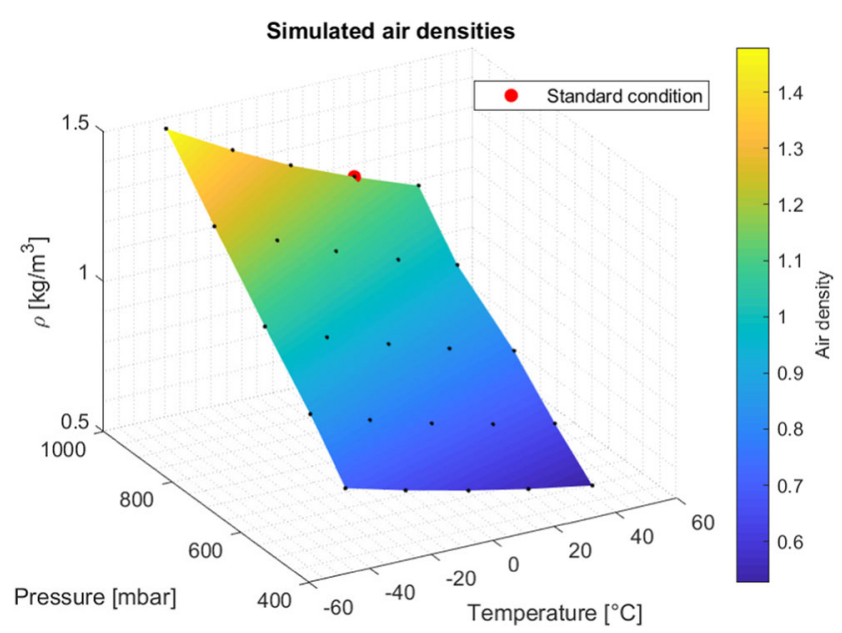

Fig. 5 Air densities corresponding to the temperature and pressure combinations set for the tests 
When setting a new temperature, all the measurements are taken after $15 \mathrm{~min}$ from reaching the set-point condition. This time is required for the stabilization of the load cell. terraXcube laboratory allows to set a temperature rate of change of $30{ }^{\circ} \mathrm{C} / \mathrm{h}$ and a rate of climb/descend of $5 \mathrm{~m} / \mathrm{s}$. To reduce testing time, we set a temperature and investigate all the altitudes at that temperature. In this way, we are able to enter inside the test section before low pressure are simulated and make the necessary adjustments if unexpected behaviours are experienced. The environmental matrix is simulated from $+40{ }^{\circ} \mathrm{C}$ to $-40{ }^{\circ} \mathrm{C}$, from sea level to the maximum altitude. When stable conditions are reached, the single rotor and full vehicle tests are executed independently. For both single rotor and complete UAS, a Remote Controller is used to set Pulse Width Modulation (PWM) signal to control the motor speed. Four throttle levels $(50 \%, 66 \%, 83 \%$ and $100 \%)$ are set for all the tests. Each throttle level is associated to a RC switch in order to allow the repeatability of the commands. Each throttle is sampled for $30 \mathrm{~s}$ for stable flow conditions. Before starting a new recording, all the sensors are checked to make sure everything is working properly.

\section{Data Reduction}

Thrust, torque, motor speed as well as electric power consumptions are the experimental data measured with the proposed setup. To highlight the impact of air temperature and pressure on performance, all the data are processed to compute the following quantities.

Thrust and torque are directly affected by air density and motor speed. For this reason, they are expressed in term of non-dimensional coefficient

$$
\begin{aligned}
& c_{T}=\frac{T}{1 / 2 \rho n^{2} D^{4}}, \\
& c_{Q}=\frac{T}{1 / 2 \rho n^{2} D^{5}},
\end{aligned}
$$

where $c_{T}$ and $c_{Q}$ are respectively the thrust and torque coefficients, $T$ and $Q$ are the propeller/full vehicle thrust and torque, $\rho$ is the air density and $D$ is the propeller diameter (reference dimension for both propeller and quadrotor test). For the isolated rotor test case, $n$ is the motor speed [rev/s]; for the full vehicle tests, $n$ is the average value of the four motor speeds [rev/s]. Furthermore, for the isolated rotor tests, it is possible to evaluate the mechanical power coefficient as

$$
c_{P}=\frac{Q \Omega}{1 / 2 \rho D^{5} n^{3}},
$$

where $\Omega$ is the motor speed in [rad/s]. As reported in [23], the relationship between torque and power coefficients is as follows

$c_{P}=2 \pi c_{Q}$.

Previous studies on propeller performance by Brandt, Selig and Deters [2, 3, 8-10] show that thrust coefficient is directly affected by Reynolds number. Due to changes in air temperature and pressure, the corresponding Reynolds is responsible for different aerodynamic performance. To this end, the Reynolds is defined as

$R_{e}=\frac{\rho \Omega R L}{\mu}$,

where $R$ is the propeller radius and $\mu$ is the air viscosity computed based on Suterland's model [18]. Finally, $\Omega$ is motor speed / average rotor speed and $L$ is the characteristic length scale defined as the propeller's chord length at $75 \% R$.

\section{Test Results}

In the following section, test results are presented and discussed Additional details and raw data are available at [29].

\subsection{Propeller Data}

Before proceeding with all the simulated atmospheres reported in Fig. 5, the T-Motor propeller thrust and torque measurements are assessed in room temperature and sea level altitude conditions with available data in literature. To this end, hover tests performed by Russell [27] with the same propeller and load cell are considered. The comparison is performed considering thrust and torque coefficients, to avoid differences in air density. Moreover, throttle signals are set to achieve the same motor speed investigated at NASA Ames (from 2500 to $4500 \mathrm{rpm}$, $500 \mathrm{rpm}$ step). Figure 6 shows there is a good overlap between our data and those from NASA. Considering the thrust coefficient (Fig. 6a), we highlight our data shows a linear trend with respect to motor speed. This is in agreement with the experimental activity performed by Brandt and Selig [2, 3] as the thrust coefficient is directly proportional to Reynolds number and therefore to the angular rate of the motor. The maximum difference between our data and those measured by NASA is lower than $10 \%$, which is acceptable considering different test stand installation and speed sensor used for the tests. In a similar way, torque coefficient in Fig. $6 \mathrm{~b}$ is almost constant, in accordance with the expected trend investigated by Brandt and Selig. The comparison with NASA torque coefficient shows a limited offset with our data being slightly smaller 


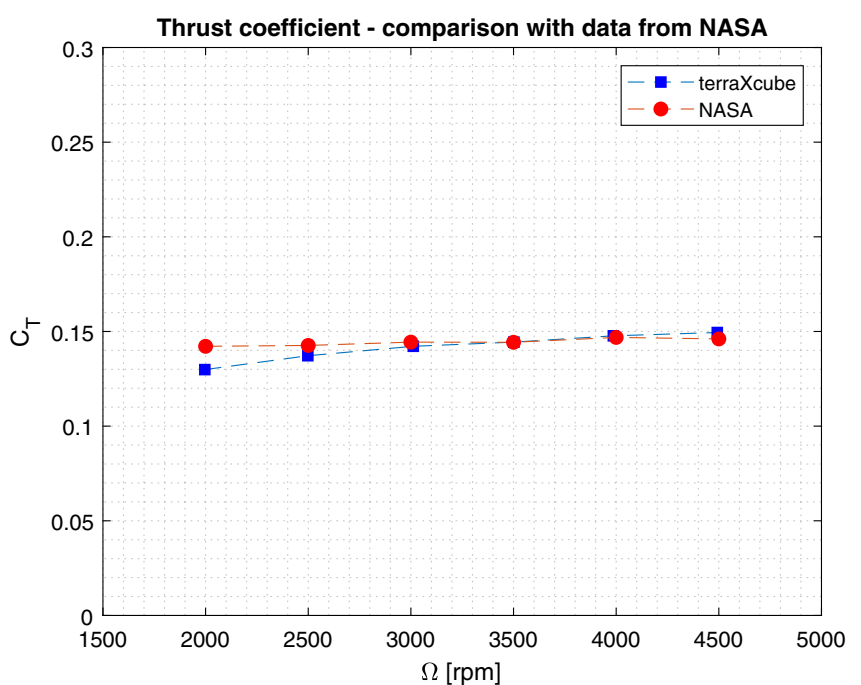

(a)

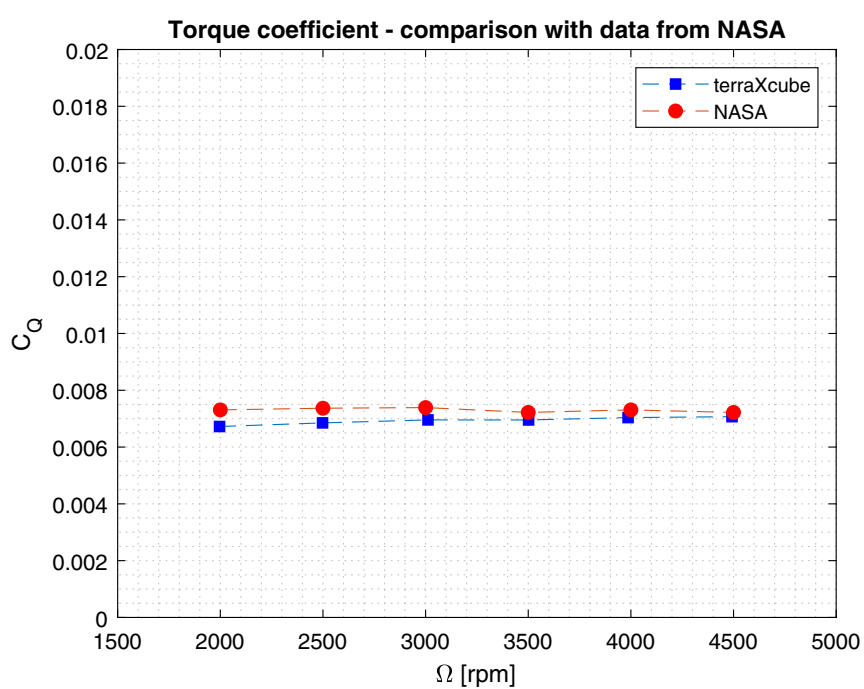

(b)

Fig. 6 Comparison between measured propeller coefficients and data from Russell et al. [27]. a Thrust coefficient b Torque coefficient

and a percentage difference lower than $9 \%$. In general, the highlighted difference in both thrust and torque coefficients are acceptable and may be related to different speed sensor used and test stand installations.

Figure 7 schematically shows thrust and motor speed data recorded for all the simulated atmospheres. Each surface in this figure corresponds to a constant throttle level set by the test engineer. Some important findings are highlighted as they provide preliminary considerations.

Firstly, at constant air temperature, thrust is directly proportional to pressure; on the other hand, considering constant pressure conditions, the propeller thrust is inversely proportional to temperature. This is a direct consequence of air density as suggested by Eq. 2 and confirmed by the thrust surface in Fig. 7a. Secondly, considering the same throttle level for all the simulated atmospheres, the angular rates in Fig. $7 \mathrm{~b}$ reveal a motor speed reduction as the air density increases. The reason of this behaviour is due to the higher torque load acting on the propeller at high pressure and low temperature.

\subsubsection{Altitude Effects at Constant Air Temperature}

Figure 8 shows the propeller thrust and mechanical power with respect to motor speed at ambient temperature $\left(20^{\circ} \mathrm{C}\right)$ for the altitudes reported in Section 3.

The dashed circle lines in Fig. 8a represent the thrust to motor speed curve. A parabolic trend is evinced and confirm thrust is proportional to the square of the motor angular rate as reported in theory [18]. Note that circles correspond to throttle levels reported. In addition, the square-marked line labelled as $T_{r e f}$ represents a reference thrust level equal to $6.5 \mathrm{~N}, 66 \%$ throttle at sea level. The corresponding motor

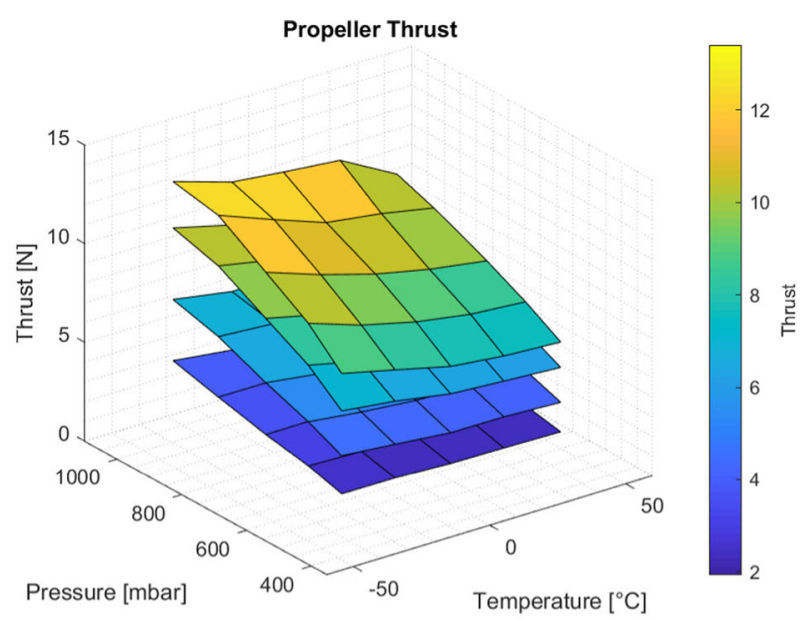

(a)

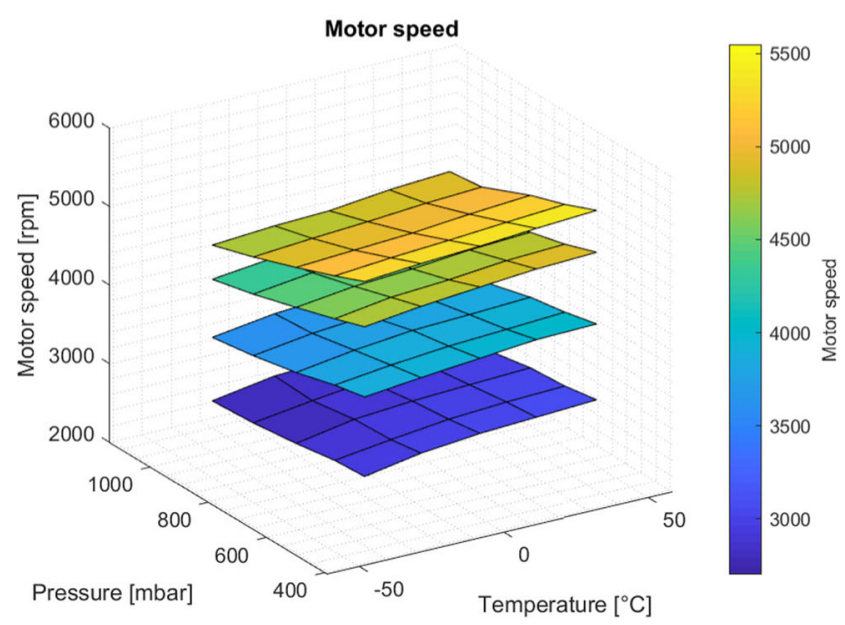

(b)

Fig. 7 Propeller thrust and torque for the simulated atmospheres. a Thrust b Motor speed 


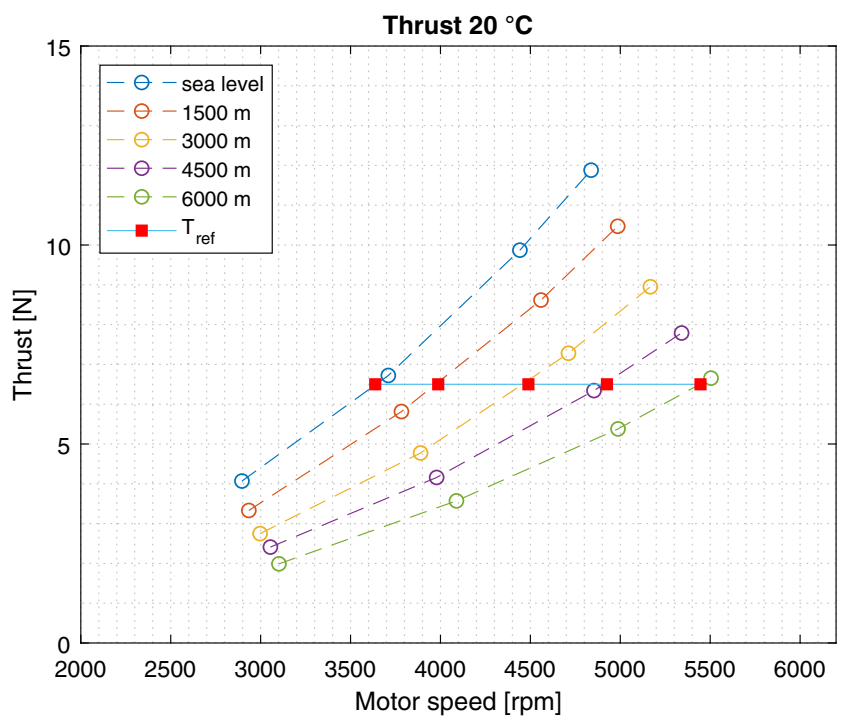

(a)

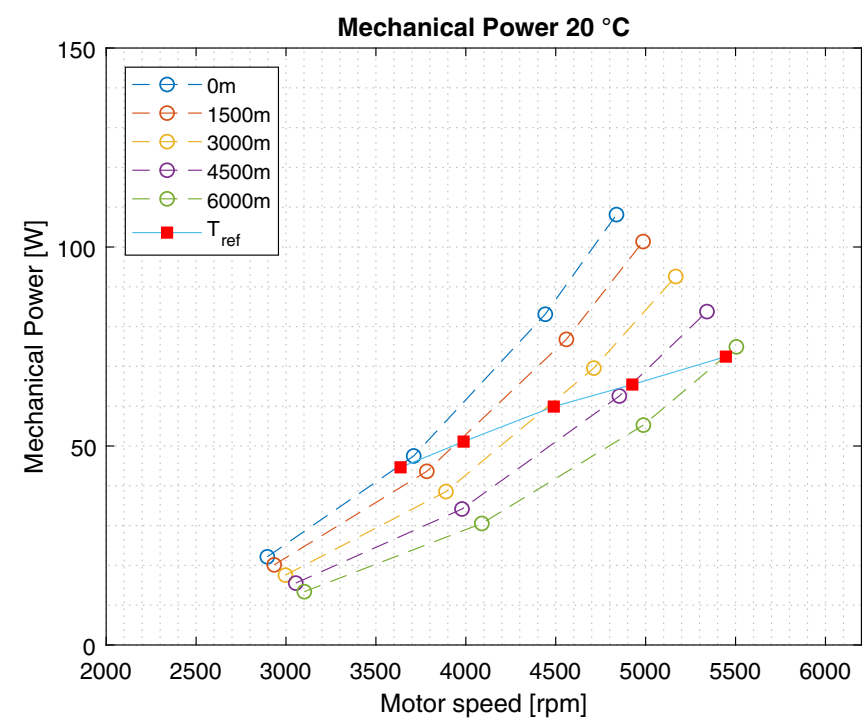

(b)

Fig. 8 Propeller thrust and mechanical power, pressure effect at constant air temperature, $20^{\circ} \mathrm{C}$. $\mathbf{a}$ Thrust $\mathbf{b}$ Mechanical power

speeds are obtained leveraging a polynomial interpolation. It can be noted that as the altitude is increased, the required motor speed to achieve the reference thrust value increases. In the most extreme case, $6000 \mathrm{~m}$ altitude, the speed increase is up to $50 \%$ compared to sea level conditions with propeller thrust closed to the maximum thrust available as the throttle is close to $100 \%$. Furthermore, increasing the altitude corresponds to higher throttle level for the desired thrust. On the other hand, a reference motor speed will result in a reduced thrust generated by the propeller.

Similar considerations are made for the mechanical power shown in Fig. 8b. As the altitude increases, the power required to achieve a reference thrust(square marks in the figure) increases too. This is a direct consequence of the higher motor speed needed for the same thrust. In addition, at $6000 \mathrm{~m}$, the mechanical power for the reference thrust is $60 \%$ more than the required power at sea level, with the throttle approximately equal to $100 \%$. Finally, the mechanical power required by the motor in full throttle condition decreases as higher altitudes are set meaning that the air density reduction prevails over motor speed increase.

The effect of altitude on motor efficiency is explored in Fig. 9 for propeller tests at $-40{ }^{\circ} \mathrm{C}$. To avoid undesired effects related to the Electronic Speed Controller, the measurements were performed setting full throttle and changing the output voltage of the power supplier, at sea level and $6000 \mathrm{~m}$ altitude. The motor efficiency is given with respect to propeller thrust. Figure 9 suggests that motor efficiency is closed to $80 \%$, a common value for UAS brushless motor [14]. Furthermore, the motor efficiency shows higher values when low pressure conditions are set at constant propeller thrust. A possible explanation for increased efficiency at higher altitude is given. It is important to highlight that the higher the altitude the faster the motor speed (Fig. 8a) and the downstream flow induced by the propeller. As a result, the convection heat transfer improves motor efficiency despite the reduced heat exchange between the motor and surrounding air as a consequence of air density decrease (i.e. $6000 \mathrm{~m}$, $-40{ }^{\circ} \mathrm{C}$ results in $50 \%$ air density reduction compared to the density at the same temperature sea level condition).

During the tests, it was noticed that when high altitudes were set the motor response to throttle commands took

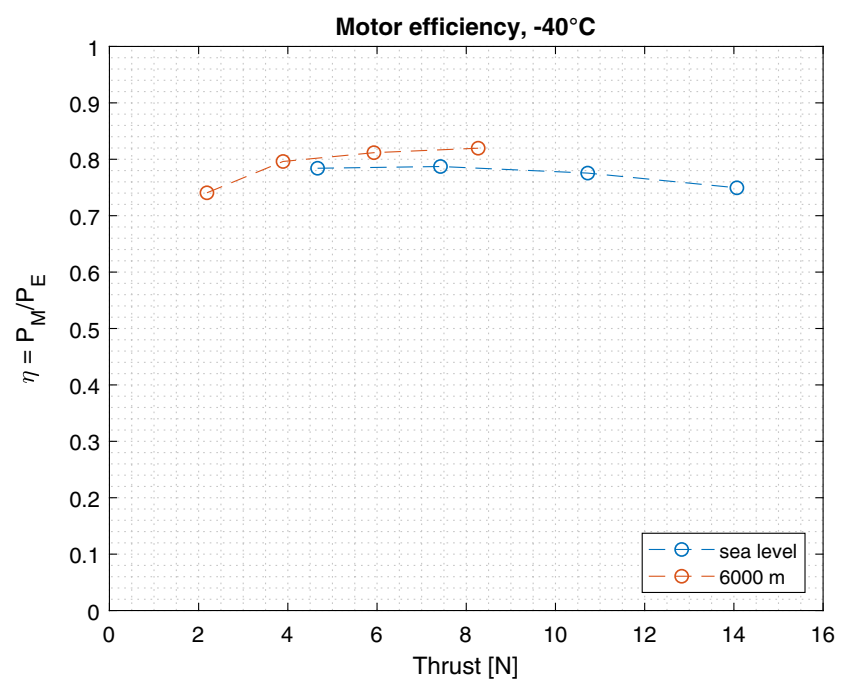

Fig. 9 Low pressure effects on motor efficiency at constant air temperature 
longer time. To investigate how low pressure conditions affect propeller and motor speed response, the mechanical time constant required to slow down the motor angular rate is computed. To evaluate the mechanical time constant, the maximum angular rate (full throttle) is considered and the corresponding time $T$ required to stop the motor (throttle instantaneous step down from $100 \%$ to $0 \%$ ) is evaluated.
The time constant $\tau$ is defined as the time required by the motor speed to reduce up to $63 \%$ of the initial value, approximately one fifth the total time $T$. A typical motor speed time history is reported in Fig. 10a; Fig. 10b shows the computed mechanical time constant as a function of altitude for a reference temperature of $+40{ }^{\circ} \mathrm{C}$. As higher altitudes are set, the time constant $\tau$ increases.
Fig. 10 Altitude effect on motor speed time constant. a Typical motor speed time history b Mechanical time constant

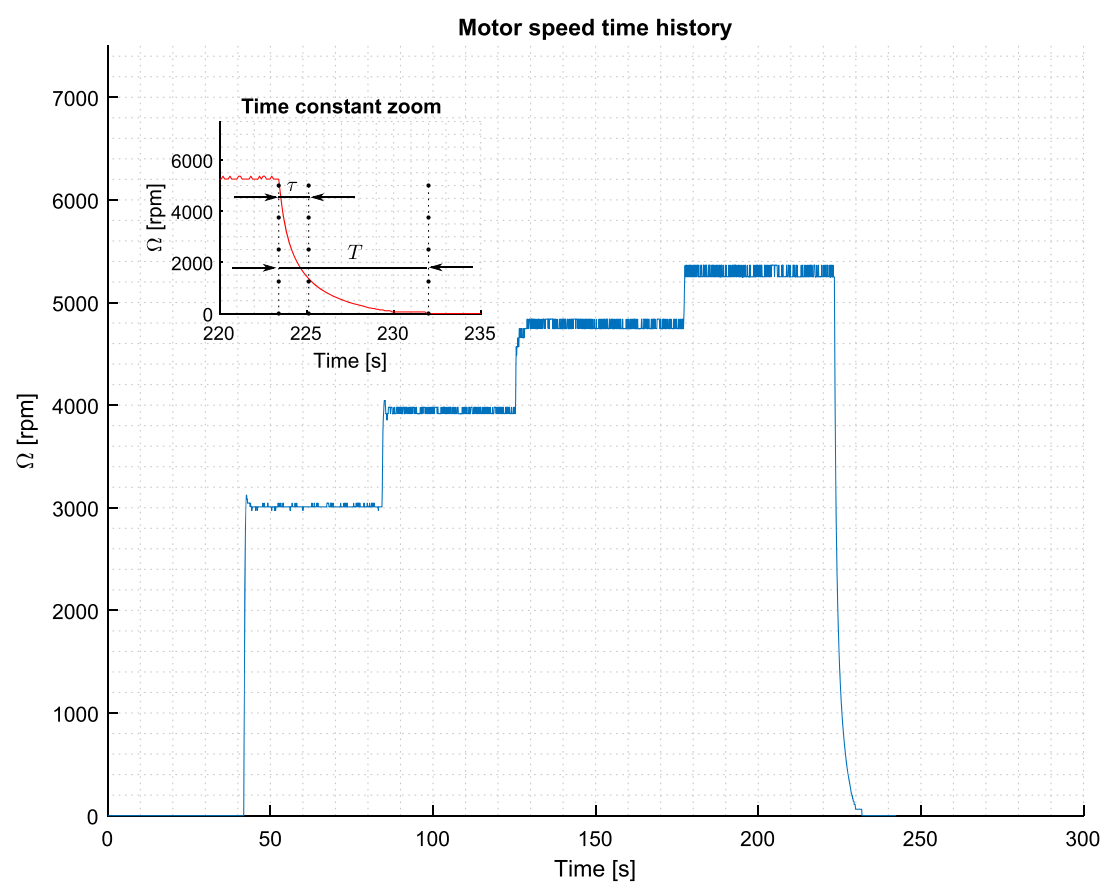

(a)

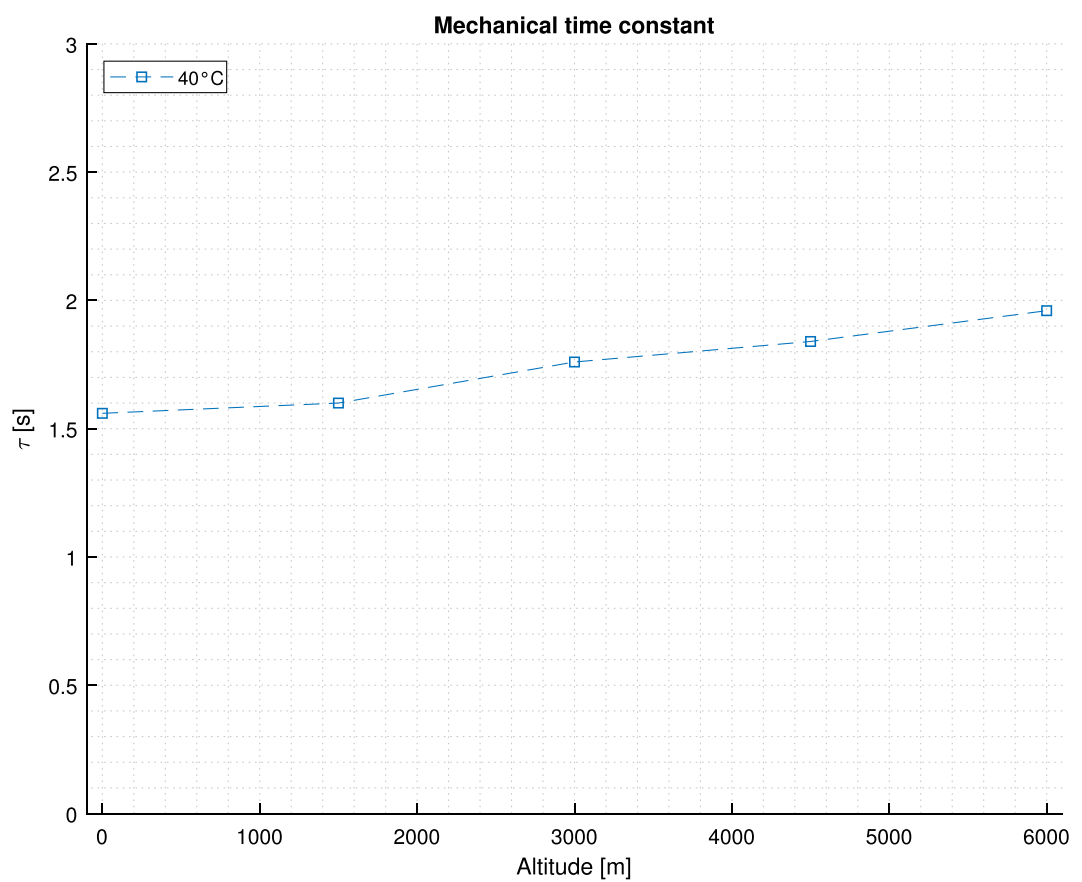

(b) 
The experimental trend of the time constant $\tau$ is validated by analytical considerations. The dynamic equilibrium governing the motor speed transient is given by the differential equation

$$
\begin{aligned}
& J \dot{\Omega}+\frac{1}{2} \rho C_{Q} D^{5} \Omega^{2}=0 \\
& \Omega\left(t_{0}\right)=\Omega_{0}
\end{aligned}
$$

where $J$ is the propeller and motor inertia, $\Omega$ is the motor angular rate, $\rho$ is the air density, $D$ is the propeller diameter, $C_{Q}$ is the torque coefficient and $\Omega_{0}$ is the initial motor speed. Equation 7 is a Cauchy problem that leads to the solution

$\Omega(t)=\frac{\Omega_{0}}{1+\frac{1 / 2 \rho C_{Q} D^{5} \Omega_{0} t}{J}}$

where it is possible to define the time constant

$\tau=\frac{2 J}{\rho C_{Q} D^{5} \Omega_{0}}$.

Finally, from Eq. 9 it can be found that the motor speed time constant is inversely proportional to air density: considering constant air temperature conditions, the lower the pressure the smaller the density and the greater the time constant $\tau$ as all the quantities are are not affected by the pressure, even the torque coefficient as it will be presented in the following paragraphs. As a result, at high altitude the propeller response to throttle command is less reactive, requiring longer time to reach the desired angular rate.

\subsubsection{Temperature Effects at Constant Altitude}

Temperature effects are investigated at constant altitude condition. Figure 11 shows propeller thrust and mechanical power for all the temperatures considering a reference altitude of $1500 \mathrm{~m}$. The square-marked line labelled as $T_{\text {ref }}$ represents a reference thrust level equal to $6.5 \mathrm{~N}, 66 \%$ throttle while the circle-dashed curves are the experimental thrust and mechanical power trend with respect to motor speed for different air temperatures. As the temperature is reduced, thrust and mechanical power generated by the propeller increase. This is a direct consequence of air density changes (increase) considering a constant pressure as stated by Eq. 2. Moreover, the reference thrust reported in Fig. 11a suggests air temperature decrease is responsible of motor speed reduction for the same thrust level. In the same way, the mechanical power (Fig. 11b) decreases when cold temperatures are set as a result of motor speed reduction to generate the reference thrust.

The air temperature is responsible for different motor performance. Firs of all, the motor and Electronic Speed Controller (ESC) resistances are directly affected by air temperature. Direct measurement of motor winding resistance for UAS propulsion system is difficult as dedicated instruments are required to collected small values, $\mathrm{m} \Omega$ order of magnitude. Further more, limited data are available from manufacturer' data-sheets. For the T-Motor MN3508 brushless motor used during the tests, a reference value of $205 \mathrm{~m} \Omega$ is reported in the technical description of the motor; this value refers to a single phase resistance without any details on temperature condition and related ESC resistance. It is possible to estimate the propulsion

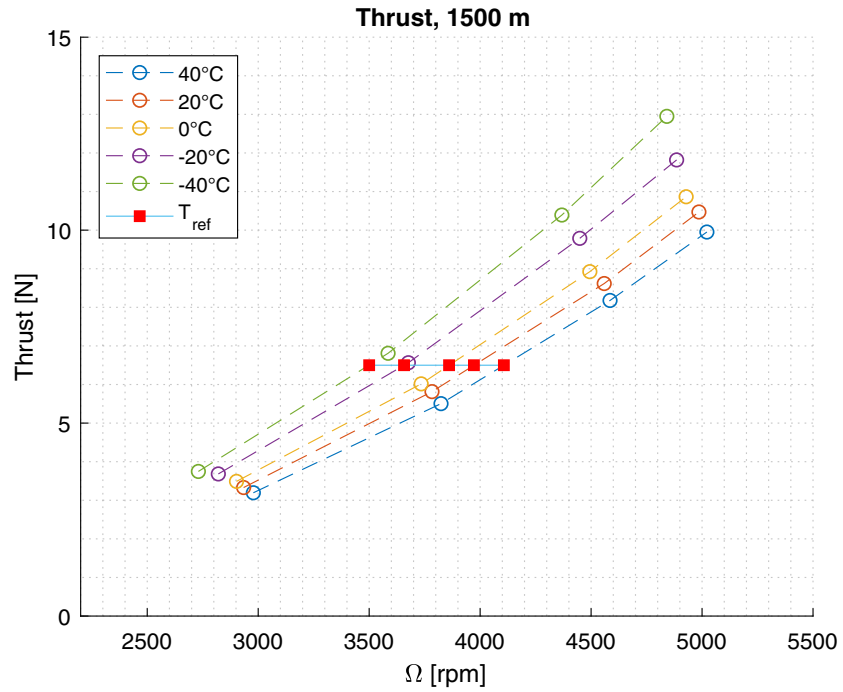

(a)

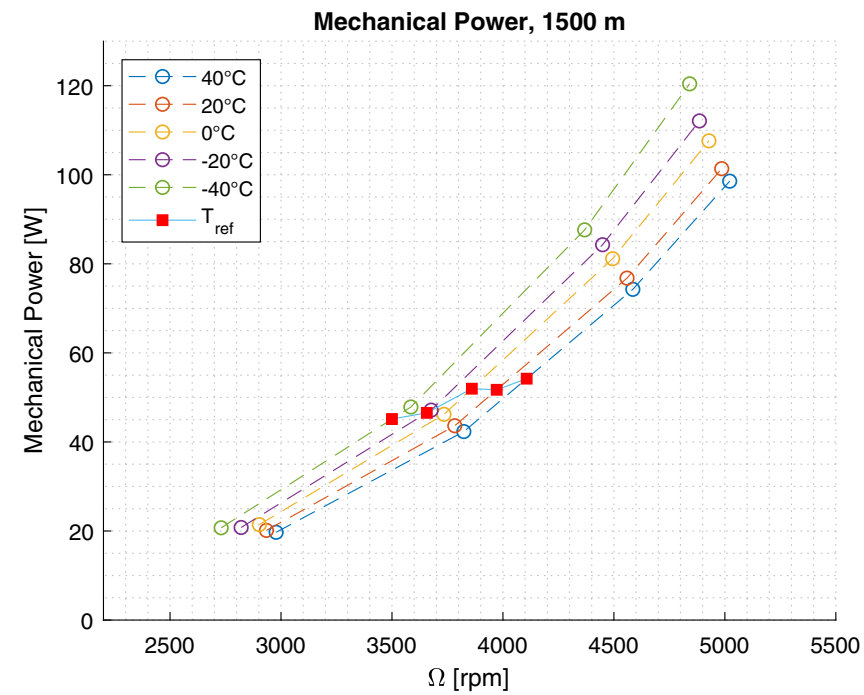

(b)

Fig. 11 Propeller thrust and mechanical power, temperature effects at constant air pressure, $1500 \mathrm{~m}$. a Thrust $\mathbf{b}$ Mechanical power 


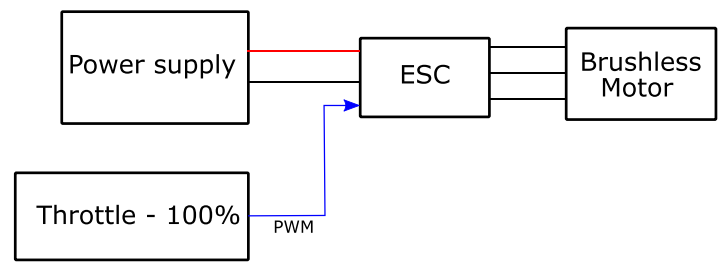

(a)

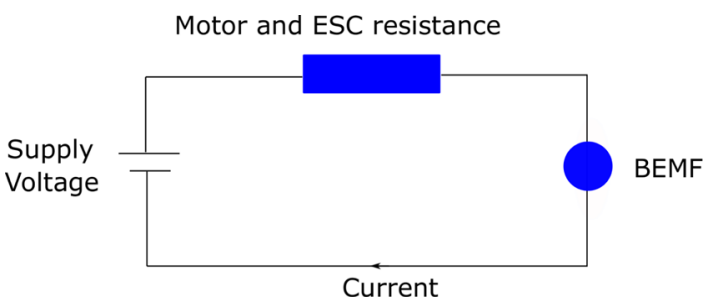

(b)

Fig. 12 Brushless motor for UAS applications. a BLDC motor schematization b Simplied electrical circuit

system resistance (motor windings and ESC) based on the electrical and mechanical power measured during the tests. To avoid undesired effects related to the Pulse Width Modulation signals, the experimental data are collected setting different power supply voltages $(8.4 \mathrm{~V}, 11.2 \mathrm{~V}$, $14 \mathrm{~V}$ and $16.8 \mathrm{~V}$ ) in full throttle conditions. The overall propulsion system is reported in Fig. 12a, while a simplified equivalent electrical circuit (first order approximation [15]) is in Fig. 12b.

Mechanical and electrical power required by the motor are computed as

$$
\begin{aligned}
& P_{M}=Q \Omega \\
& P_{E}=V i
\end{aligned}
$$

where $Q$ is the motor torque, $\Omega$ the speed, $V$ is the supply voltage and $i$ is the electrical current. The difference between electrical and mechanical power is the amount of power dissipated by Joule effect. The motor and ESC resistance $R_{t o t}$ is give by the following Equation:

$R_{t o t}=\frac{P_{E}-P_{M}}{i^{2}}$.

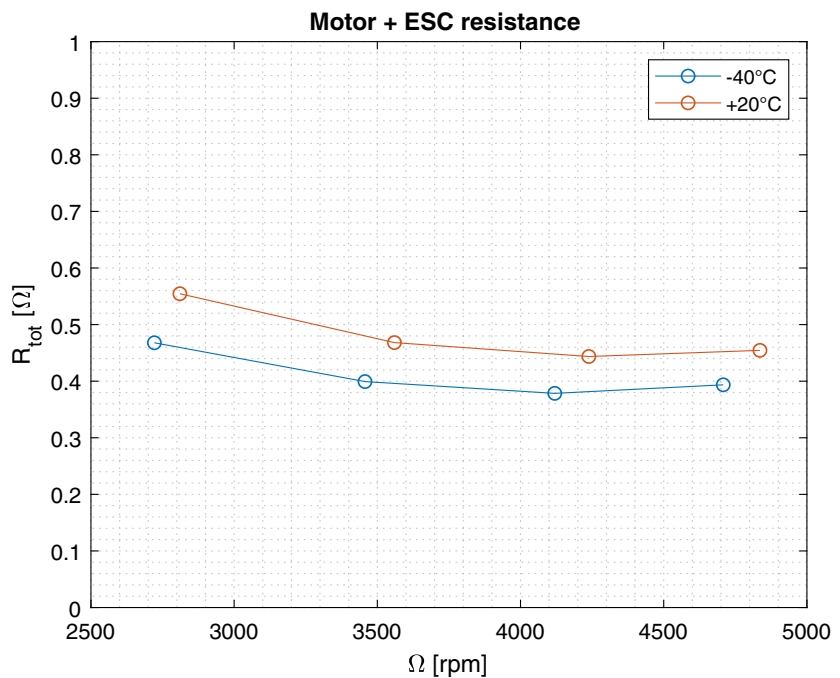

Fig. 13 Temperature effect on motor and ESC resistance
The resistor is directly affected by temperature and a linear relationship is usually assumed [32], so that the colder the environment the lower the motor and ESC resistance is expected. The experimental data estimated in Fig. 13 confirms the this behaviour showing a $15 \%$ reduction at $-40{ }^{\circ} \mathrm{C}$ compared to ambient temperature.

Temperature is responsible also for no load current changes. This is the electrical current required to spin the motor without any loads applied to its shaft. It provides an estimate of the bearing friction power loss and viscous drag due to rotor spinning in the air. The higher the no load current, the less efficient is the motor as more power is dissipated during the electrical to mechanical conversion. To evaluate the no load current, the propeller is removed and different throttles are set to the ESC. The experimental data are in Fig. 14, where the no load current is given with respect to the motor speed. The lower the temperature, the higher the no load current meaning that the viscous friction increases.

Finally, temperature effect on motor efficiency is in Fig. 15. Low ambient temperature results in degraded motor efficiency as a result of increased no load current.

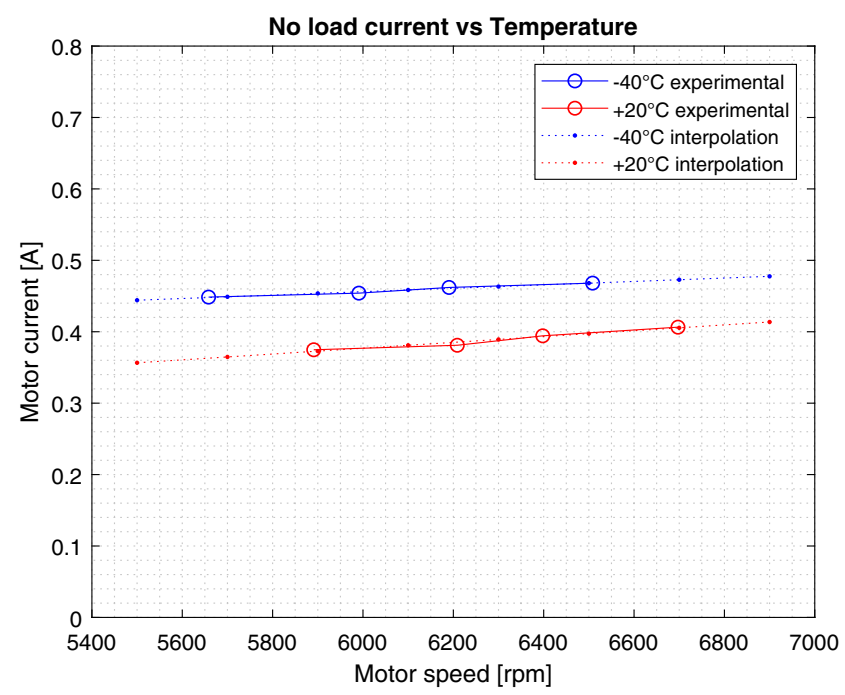

Fig. 14 Temperature effect on no load current 


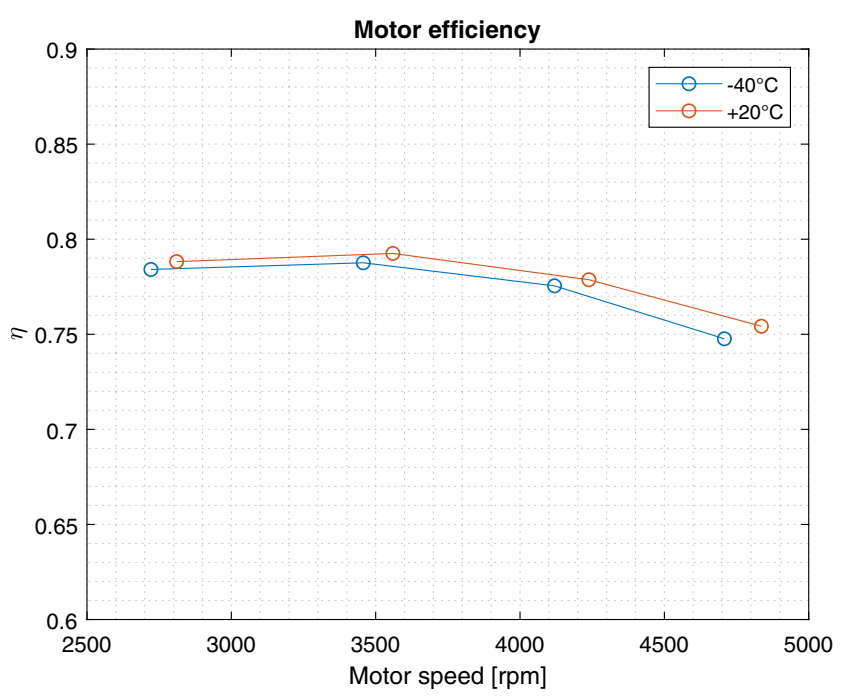

Fig. 15 Temperature effect on motor efficiency

\subsubsection{Propeller Coefficients and Reynolds Number}

Propeller thrust and torque coefficients are evaluated Eq. 3 for all throttle levels and simulated atmospheres with respect to the corresponding Reynolds number. The experimental data are shown in Fig. 16.

The high Reynolds numbers represents full throttle, low temperature and sea level test conditions, while low Reynolds numbers arise for high temperature, low pressure and 50\% throttle test cases. The black square markers in Fig. 16 correspond to thrust and torque coefficients at $+20{ }^{\circ} \mathrm{C}$, sea level and $66 \%$ throttle (reference condition). Considering the thrust coefficient in Fig. 16a, a linear trend is highlighted as the Reynolds increases, in accordance to experimental data available in literature for propeller testing in wind tunnels $[2,3,9,10]$. Compared to the reference condition, high Reynolds number result in $10 \%$ thrust coefficient increase, while a reduction of $8 \%$ is achieved for low Reynolds. The corresponding linear interpolation is

$C_{T}\left(R_{e}\right)=C_{T_{0}}+k R_{e}$,

where $C_{T_{0}}$ is 0.1202 and $k$ is equal to $1.6221 E-07$.

The torque coefficient in Fig. 16b shows a constant trend with respect to Reynolds numbers. The behaviour is the same as for experimental data in literature. Finally, the mechanical power coefficient is computed based on Eq. 4 and reflects the constant trend of the torque coefficient.

As reported by the experimental activity carried out on low Reynolds performance of small scale UAS propeller [2, 3, 9, 10], the Reynolds number affects lift and drag coefficients of the propeller airfoils. When low Reynolds conditions occur, the aerodynamic performance are degraded by the laminar separation bubble [21] which is responsible for the airfoil lift coefficient reduction and

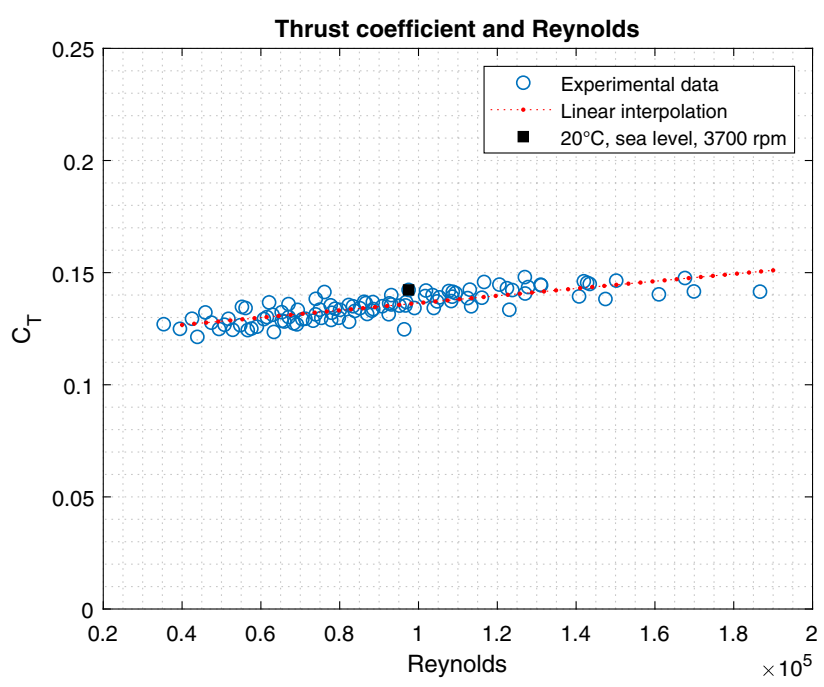

(a)

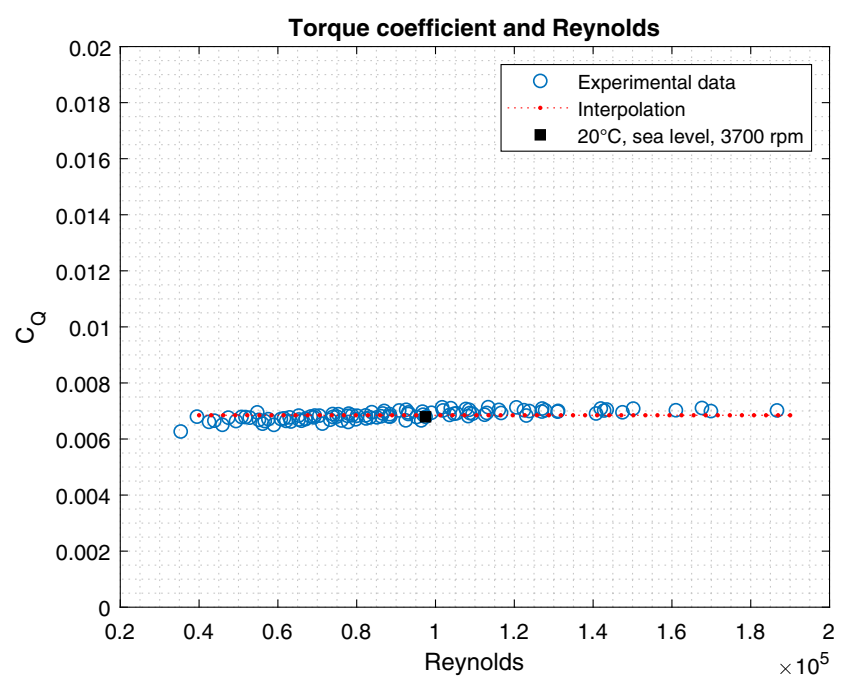

(b)

Fig. 16 Propeller thrust and torque coefficients. a Thrust coefficient b Torque coefficient

increased drag coefficient. It is important to highlight that the propeller thrust $C_{T}$ is obtained integrating a non linear combination of sectional lift/drag coefficients and inflow angle along the propeller radius. As a result, the effect of low Reynolds due to the laminar separation bubble is to degrade the overall propeller thrust coefficient $C_{T}$.

Propeller performance are usually predicted using Blade Element Momentum Theory or Computational Fluid Dynamics. In both approaches, detailed geometrical data of the propeller are needed, such as blade twist and chord distributions as well as sectional airfoil shapes. The aforementioned data are usually not provided by manufacturers and limited data are available in literature. For these reasons, the development of propeller physical simulation models are not trivial. Geometrical data of the propeller involved in this study were collected by Russell 
using a 3D laser scanner [28]. Considering the BEMT tool, additional data are needed: lift and drag coefficients as a function of the Angle of Attach (AoA) and Reynolds numbers according to the airfoil shape. These data cannot be easily estimated, especially when low Reynolds numbers are considered. Moreover, for the T-Motor propeller, a continuous varying airfoils from hub to tip is used. The BEMT implementation reported in [29] shows the model is able to predict propeller performance when conventional weather conditions are set, while high error estimate arise when low Reynolds numbers are considered. This is related to the aerodynamic database estimated using standard engineering tools which are not able to account for laminar separation bubble conditions.

In this work, a black box model is built using TensorFlow [35] to solve a regression problem. Propeller thrust coefficient experimental data and corresponding Reynolds numbers are split in training (70\%), testing $(15 \%)$ and validating $(15 \%)$ sets. The experimental data are randomly shuffled and normalized before performing any computation. A sequential model with dense layers is leveraged as this is the most common network architecture. The network structure consists of two layers as reported in Fig. 17, where the red circle is the input Reynolds number while the green circle represents the estimated thrust coefficient. In total, 13 parameters must be estimated during model training.

Model performance are reported in Fig. 18, where the loss function is shown. The epoch number is set to 100 to avoid data overfitting; the loss function used is the mean square error (MSE). From Fig.18, the loss function rapidly decreases over the first 60 epochs suggesting the model is able to predict the experimental data. Figure 19 compares the experimental data and the predictions of the model over a range of Reynolds numbers. Thrust coefficients predicted by the model shows the network is able to estimate propeller $C_{T}$ over the Reynolds numbers of interest.

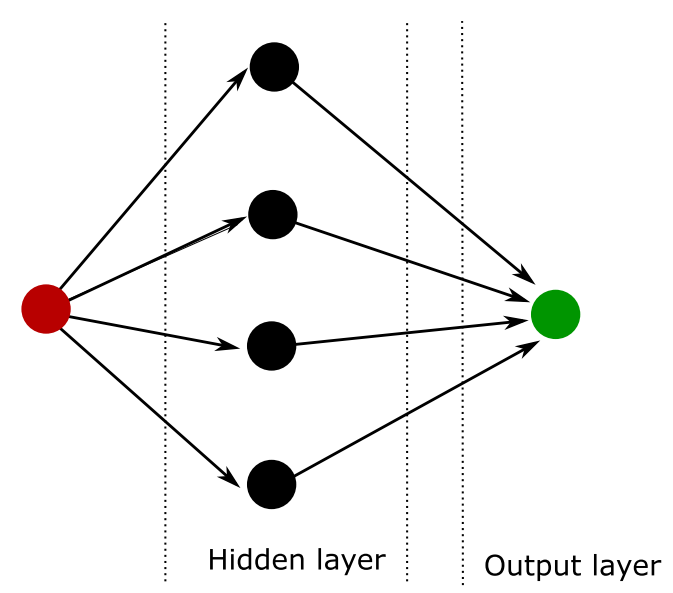

Fig. 17 Network architecture for propeller thrust coefficient estimate

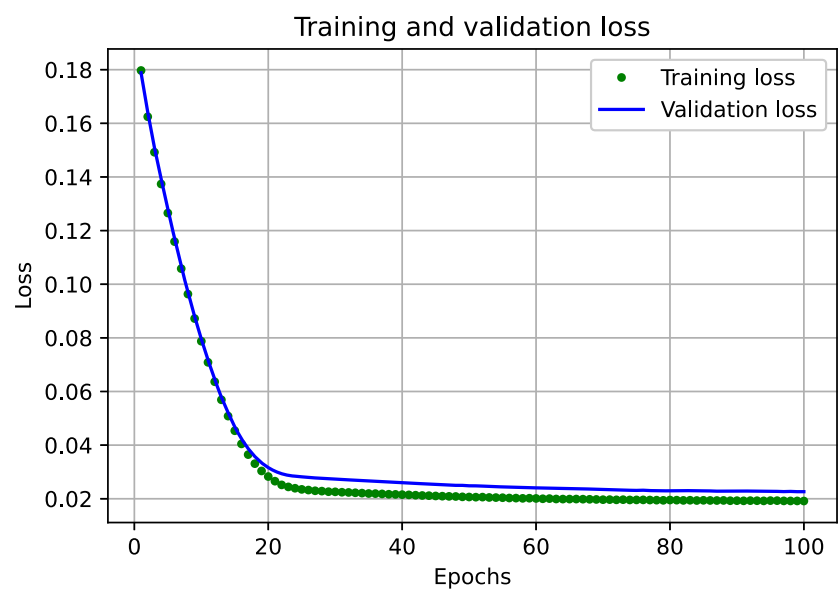

Fig. 18 Loss function

\subsection{Full Vehicle Test Configuration}

Full vehicle tests have been presented in our previous work [30]. In this article, a more in depth comparison between the isolated rotor and full vehicle thrust performance is discussed. The vehicle under test is a quad $-x$ UAS with motor directions paired two-by-two, as for conventional quadrotor. For this reason, the overall torque acting on the vehicle is zero and it is not possible to evaluate the mechanical power. However, it is possible to introduce the electrical power coefficient $c_{P_{E}}$ as

$c_{P_{E}}=\frac{V i}{1 / 2 \rho D^{5} n^{3}}$,

where $V$ is the voltage and $i$ the total electrical current. $c_{P_{E}}$ provides details on the overall vehicle performance, the mechanical power required by the propellers and the conversion from the electrical power supply.

Full vehicle thrust and electrical power coefficients are given in Fig. 20 for all the simulated atmospheres. The circle markers represent experimental data, the dotted lines

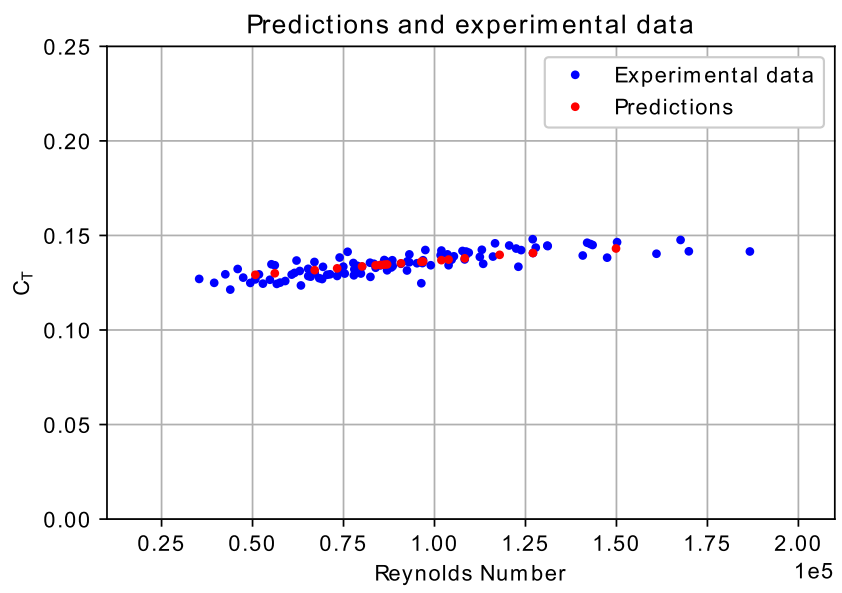

Fig. 19 Thrust coefficient predictions and experimental data 


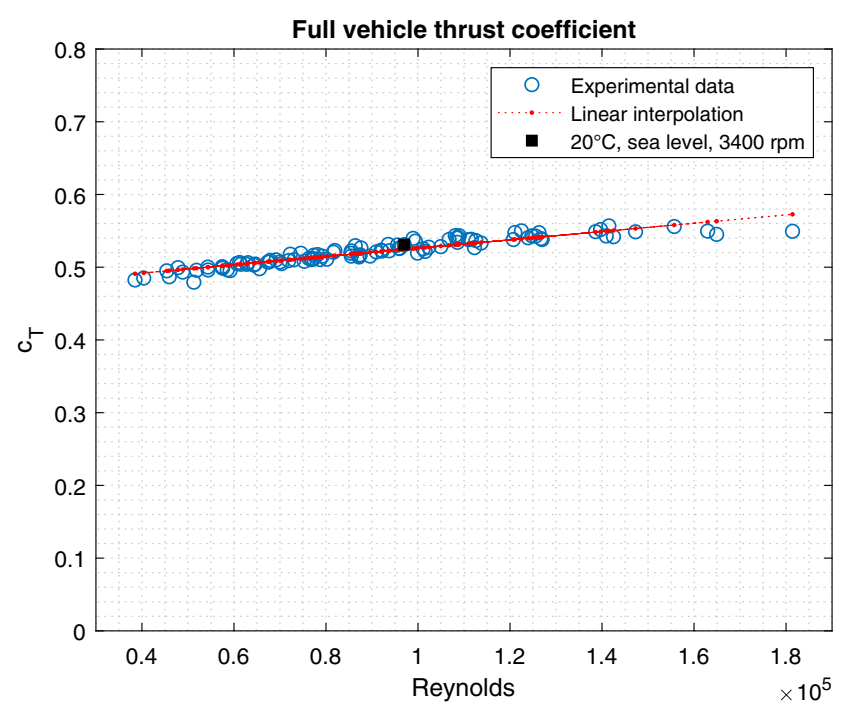

(a)

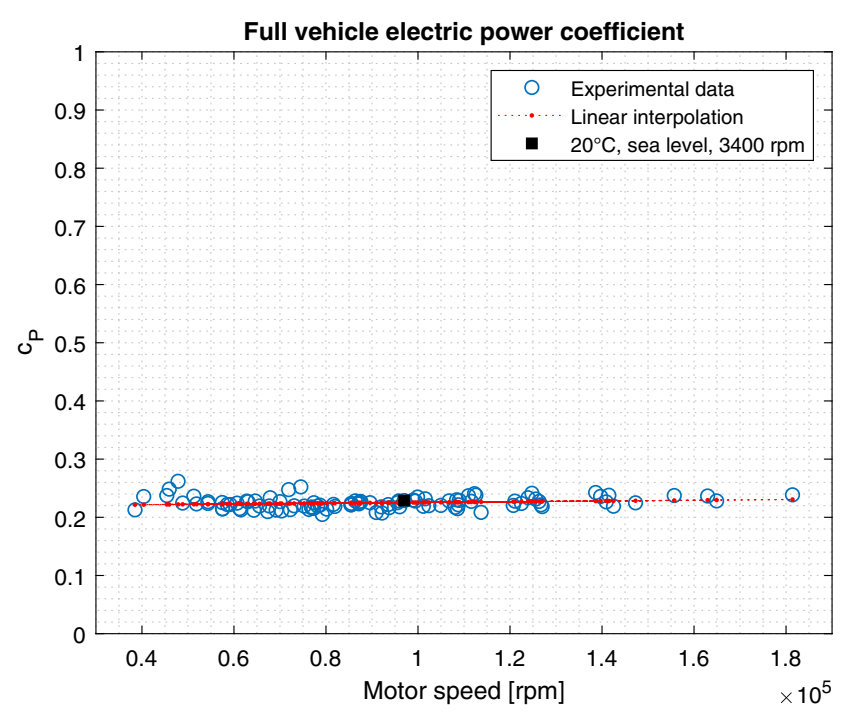

(b)

Fig. 20 Full vehicle thrust and electrical power coefficients. a Thrust coefficient b Electrical power coefficient

are linear interpolation and the black square markers show thrust and power coefficients for a reference test condition of $+20{ }^{\circ} \mathrm{C}$ sea level and $66 \%$ throttle. The Reynolds number range is essentially the same as for the isolate rotor as the average motor speed of the four rotors is used and the propeller chord at $75 \%$ is still considered the reference dimension for Reynolds computation.

Thrust coefficient in Fig. 20a reveals a linear trend with respect to Reynodlds, with lower values corresponding to high altitude and temperature as well as low throttle commands. With respect to the reference condition, high Reynolds numbers result in thrust coefficient increase up to $8 \%$; similar percent values are experienced for $C_{T}$ reduction when considering low Reynolds. Thrust coefficient interpolation with respect to Reynolds number is given by the following Equation

$C_{T}\left(R_{e}\right)=C_{T 0}+k R_{e}$,

where $C_{T 0}$ is 0.469 and $k$ is equal to $5.7174 E-7$. Considering the electrical power coefficient $c_{P_{E}}$ in Fig. 20b, the experimental data fit a flat curve suggesting that the power coefficient is not affected by Reynolds, as expected for the isolated rotor tests.

Figure 21a shows the comparison between propeller and full vehicle thrust coefficients, where the green square markers are the isolated rotor $C_{T_{\text {prop }}}$, the red star markers represent full vehicle data $\left(C_{T_{U A S}}\right)$ and the blue circles are four times the isolated propeller thrust coefficient. The Figure suggests $C_{T_{U A S}}$ is smaller compared to the isolated rotor $4 C_{T}$ owing to aerodynamic interference between multiple rotors and airflow interaction with the vehicle arm and airframe. To compare UAS and isolated rotor, the download factor $D L$ is defined as [27]

$D L=\frac{C_{T_{U A S}}-4 C_{T_{p r o p}}}{4 C_{T_{\text {prop }}}}$.

Figure 21b shows the $D L$ as a function of Reynolds number. The experimental data from vehicle and single rotor result in a decreasing $D L$ with increasing Reynolds, with an average value closed to $96.5 \%$ and a maximum difference of $94.3 \%$ for high Reynolds. The $D L$ curve is in accordance with the experimental measurements performed at NASA Ames [27] and the general trend suggests the higher the Reynolds the stronger the aerodynamic interaction between the rotor resulting in worsen $C_{T}$ values.

\section{Conclusions}

This article presents experimental data on a isolated propeller as well as quadrotor UAS performance in a climate-controlled facility. Pressure and temperature conditions are simulated inside terraXcube laboratory and a total of 25 atmosphere are considered. Thrust, torque, motor speed and electrical measurements are collected to explore propulsion system performance with a systematic approach. The experimental setup is improved in order to avoid undesired effects on sensors, with particular regard to load cell, shunt resistors and optical tachometers.

The experimental data are presented in terms of propeller and quadrotor coefficients as a function of Reynolds number. In accordance to experimental data available, the $C_{T}\left(R_{e}\right)$ curve shows a linear trend with increasing Reynolds confirming worsen propeller and vehicle thrust capabilities at low Reynolds. The reason of this behaviour is related to the laminar separation bubble occurring at low Reynolds. 


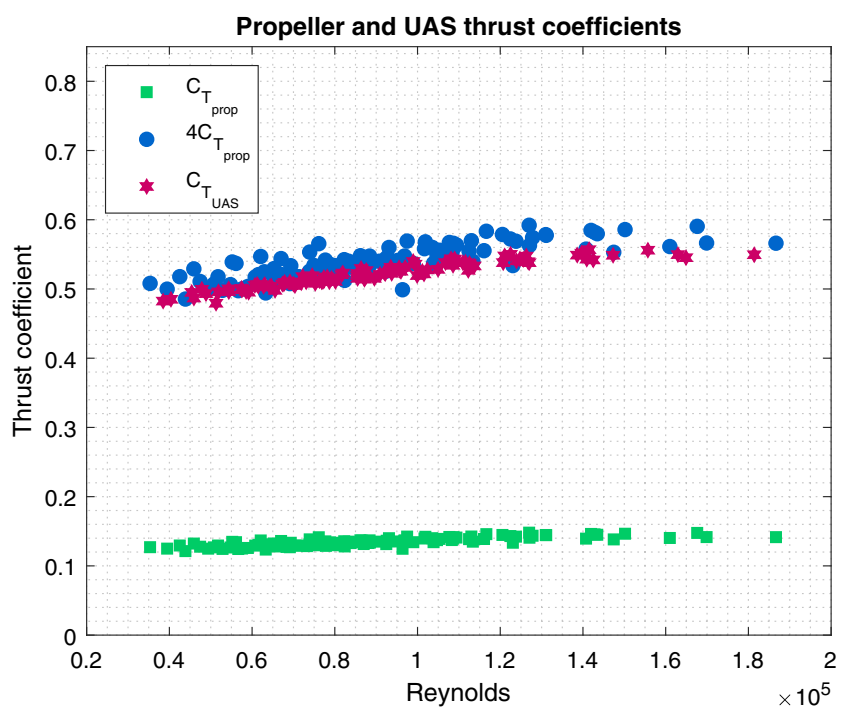

(a)

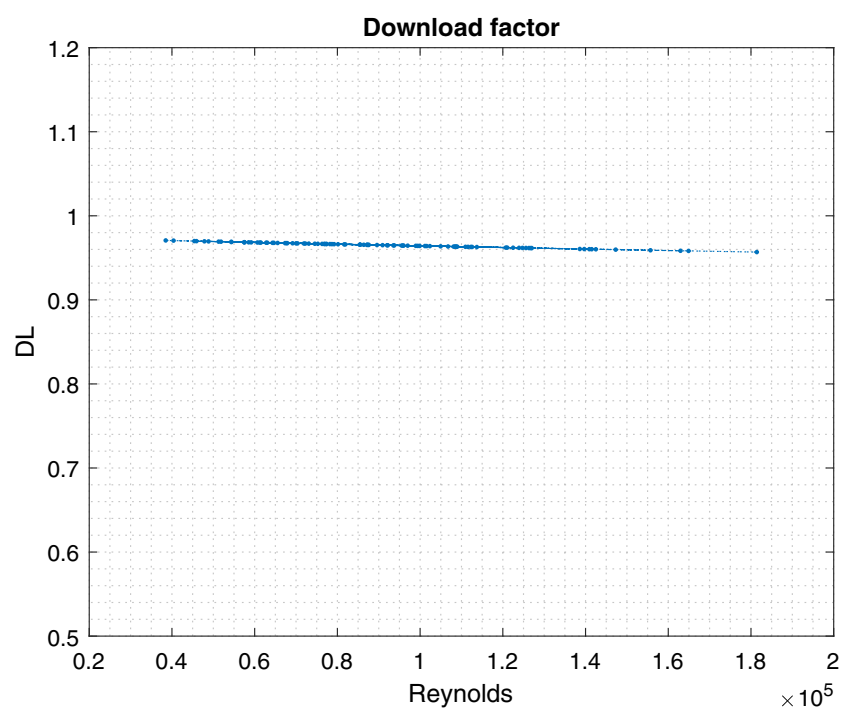

(b)

Fig. 21 Comparison between single rotor and UAS thrust coefficients. a Absolute thrust coefficients b Relative values

On the other hand, torque and power coefficients are not affected by the surrounding air atmospheres.

Details on brushless motor performance are provided at different altitude and temperature. As the air density decreases, the motor response to throttle commands experience longer time constants meaning that the propeller and vehicle are less reactive to pilot commands. Moreover, low temperature are responsible for reduced motor and ESC resistance but increased no-load current, resulting in worsen motor efficiency in cold environmental conditions. The comparison between isolated propeller and quad-rotor UAS shows the aerodynamic interaction with the vehicle airframe is responsible for a reduction in the vehicle thrust coefficient up to $5.7 \%$ compared to isolated propeller performance.

Future works include additional tests to evaluate icing conditions and their effect on thrust as well power coefficients. The final goal is to collect a high quality set of data of unmanned vehicles performance in unconventional atmospheres. Other important effects, such as temperature influence on batteries, will be examined for fine modelling of the propulsion system. The experimental activity will be leveraged to answer some of the open questions related to safety of operations in harsh weather conditions.

Acknowledgements The authors would like to thank terraXcube Eurac Research staff for their support and collaboration during test activities.

Author Contributions Conceptualization, M.Scanavino, A.Vilardi and G.Guglieri; methodology, M.Scanavino, A.Avi, A.Vilardi and G.Guglieri; experimental test preparation and execution, M.Scanavino and A.Avi; formal analysis, M.Scanavino; resources, A.Vilardi and G.Guglieri; writing-original draft preparation, M.Scanavino; writing-review and editing, M.Scanavino; supervision, A.Vilardi and
G.Guglieri; project administration, A.Vilardi and G.Guglieri; funding acquisition, A.Vilardi and G.Guglieri.

Funding Open access funding provided by Politecnico di Torino within the CRUI-CARE Agreement. The research leading to these results has received funding from the European Regional Development Fund 2014-2020, under Grant Agreement 2223/2017/Project number FESR1048, Creazione di un servizio di sviluppo tecnico per droni testati per il funzionamento in condizioni ambientali estreme, DronEx.

Availability of data and materials Not applicable.

\section{Declarations}

Ethical Approval Not applicable.

Consent to Participate Not applicable.

Consent for Publication All authors have read and agreed to the published version of the manuscript.

Conflict of Interest The authors declare that they have no conflict of interest.

Open Access This article is licensed under a Creative Commons Attribution 4.0 International License, which permits use, sharing, adaptation, distribution and reproduction in any medium or format, as long as you give appropriate credit to the original author(s) and the source, provide a link to the Creative Commons licence, and indicate if changes were made. The images or other third party material in this article are included in the article's Creative Commons licence, unless indicated otherwise in a credit line to the material. If material is not included in the article's Creative Commons licence and your intended use is not permitted by statutory regulation or exceeds the permitted use, you will need to obtain permission directly from the copyright holder. To view a copy of this licence, visit http://creativecommons. org/licenses/by/4.0/. 


\section{References}

1. Aggarwal, S., Kumar, N.: Path planning techniques for unmanned aerial vehicles: a review, solutions, and challenges. Comput. Commun. 149, 270-299 (2020)

2. Brandt, J., Selig, M.: Propeller performance data at low reynolds numbers. In: 49th AIAA Aerospace Sciences Meeting Including the New Horizons Forum and Aerospace Exposition, p. 1255 (2011)

3. Brandt, J.B.: Small-scale propeller performance at low speeds. $\mathrm{Ph}$.D. thesis, University of Illinois at Urbana-Champaign (2005)

4. Cheeseman, I., Bennett, W.: The effect of the ground on a helicopter rotor. R \& M 3021 (1957)

5. Conyers, S.A.: Empirical evaluation of ground, ceiling, and wall effect for small-scale rotorcraft. Ph.D. thesis, University of Denver (2019)

6. Danis, R.: Investigating forward flight multirotor wind tunnel testing in a 3-by 4-foot wind tunnel. Master's thesis, California Polytechnic State University (2018)

7. Delta-OHM: Specification sheet hd9408.3b sensor. https://www. deltaohm.com/en/wp-content/uploads/document/DeltaOHM-HD9408. 3B-precision-barometer-datasheet-en.pdf (2019)

8. Deters, R.: Performance and slipstream characteristics of smallscale propellers at low reynolds numbers. Ph.D. thesis, University of Illinois at Urbana-Champaign (2014)

9. Deters, R., Selig, M.: Static testing of micro propellers. In: 26th AIAA Applied Aerodynamics Conference, p. 6246 (2008)

10. Deters, R.W., Ananda Krishnan, G.K., Selig, M.S.: Reynolds number effects on the performance of small-scale propellers. In: 32nd AIAA Applied Aerodynamics Conference, p. 2151 (2014)

11. Elektronik, E.: Specification sheet e211 sensor. http://www.epluseus.com/en/products/humidity-instruments/humidity-transmittersfor-hvac-applications/ee211/ (2019)

12. Foster, J.V., Miller, L.J., Busan, R.C., Langston, S., Hartman, D.: Recent nasa wind tunnel free-flight testing of a multirotor unmanned aircraft system. In: AIAA Scitech 2020 Forum, p. 1504 (2020)

13. Fraga-Lamas, P., Ramos, L., Mondéjar-Guerra, V., FernándezCaramés, T.M.: A review on iot deep learning uav systems for autonomous obstacle detection and collision avoidance. Remote Sens. 11(18), 2144 (2019)

14. Gong, A., Verstraete, D.: Experimental testing of electronic speed controllers for uavs. In: 53rd AIAA/SAE/ASEE Joint Propulsion Conference, p. 4955 (2017)

15. Gur, O., Rosen, A.: Optimizing electric propulsion systems for unmanned aerial vehicles. J. Aircr. 46(4), 1340-1353 (2009)

16. Hann, R.: Uav icing: ice accretion experiments and validation. Tech. rep., SAE Technical Paper (2019)

17. Hann, R., Wenz, A., Gryte, K., Johansen, T.A.: Impact of atmospheric icing on uav aerodynamic performance. In: 2017 Workshop on Research, Education and Development of Unmanned Aerial Systems (RED-UAS), pp. 66-71. IEEE (2017)

18. Houghton, E.L., Carpenter, P.W.: Aerodynamics for Engineering Students. Elsevier (2003)

19. Ipetronik: Ipetronick specification sheet. https://www.ipetronik. com/products.html (2020)

20. Axis Load Cell Systems, J.M.: Specification sheet 30e15 f/t sensor. https://www.jr3.com/resources/specification-sheets (2019)

21. Lorefice, L., Pralio, B., Quagliotti, F.: Fluorescent oil flow visualization technique applied to $2 \mathrm{~d}$ airfoils at very low reynolds numbers (2004)

22. Mascarello, L.N.: Analysis and development of harmless suas (small unmanned aerial systems). Ph.D. thesis, Politecnico di Torino (2018)

23. McCormick, B.W.: Aerodynamics, Aeronautics, and Flight Mechanics. Wiley, New York (1995)

24. Murata-Power: $50 \mathrm{mv}$ and $100 \mathrm{mv}$ base-mounted dc shunts. https:// docs.rs-online.com/d2c9/0900766b81362844.pdf (2019)
25. Niedrist, G., Nollo, A., Brugger, H., Vilardi, A., Leitinger, G., Tappeiner, U.: terraxcube: an emerging ecotrone to converge chamber experiments and environmental studies in alpine ecology. In: EGU General Assembly Conference Abstracts, vol. 20, p. $13616(2018)$

26. Pedro, D., Mora, A., Carvalho, J., Azevedo, F., Fonseca, J.: Colanet: a uav collision avoidance dataset. In: Doctoral Conference on Computing, Electrical and Industrial Systems, pp. 53-62. Springer (2020)

27. Russell, C.R., Jung, J., Willink, G., Glasner, B.: Wind tunnel and hover performance test results for multicopter uas vehicles. Tech. rep., NASA Ames (2016)

28. Russell, C.R., Sekula, M.K.: Comprehensive analysis modeling of small-scale uas rotors. Tech. rep., NASA Ames (2017)

29. Scanavino, M.: Design and testing methodologies for uavs under extreme environmental conditions. Ph.D. thesis, Politecnico di Torino. Submitted, under review (2020)

30. Scanavino, M., Avi, A., Vilaradi, A., Guglieri, G.: Uas testing in low pressure and temperature conditions. In: International Conference on Unmanned Aircraft Systems (ICUAS) (2020)

31. Scanavino, M., Vilardi, A., Guglieri, G.: An experimental analysis on propeller performance in a climate-controlled facility. J. Intell. Robot. Syst. 1-13 (2020)

32. Sebastian, T.: Temperature effects on torque production and efficiency of pm motors using ndfeb magnets. IEEE Trans. Ind. Appl. 31(2), 353-357 (1995)

33. Sick: Photoelectric sensor wla16p. https://www.sick.com/it/it/ sensori-fotoelettrici/sensori-fotoelettrici/w16/wla16p-24162100a00/ $\mathrm{p} / \mathrm{p} 512654$ (2019)

34. T-Motor: T-motor brushless motor mn3508. http://store-en.tmotor. com/goods.php?id=354 (2020)

35. TensorFlow: Tensorflow. https://www.tensorflow.org/ (2020)

36. terraXcube: terraxcube-large cube datasheet. https://terraxcube. eurac.edu/about-us/\#structure (2019)

37. Zohdi, T.: The game of drones: rapid agent-based machinelearning models for multi-uav path planning. Comput. Mech. 65(1), 217-228 (2020)

Publisher's Note Springer Nature remains neutral with regard to jurisdictional claims in published maps and institutional affiliations.

Matteo Scanavino is currently a Ph.D. n Aerospace Engineering at the Politecnico di Torino, Italy. He received his B.S. and M.S. in Aerospace Engineering from Politecnico di Torino in 2014 and 2016, respectively. His research interests include autonomous indoor navigation, autopilot development and implementation as well as performance analysis of unmanned aerial vehicles.

Arrigo Avi is a UAS firefighter's pilot that aims to research on involving and challenging topics. He received a B.S. and M.S. in Aerospace Engineering from Politecnico di Milano. His research includes many aspects regarding UAV in particular: icing, distributed fleets and unusual configurations.

Andrea Vilardi, $\mathrm{PhD}$ in Cognitive and Brain Science, is senior researcher at terraXcube, Eurac Research, Bolzano, Italy.

Giorgio Guglieri is currently a Full Professor of Politecnico di Torino, Italy, in the Department of Mechanical and Aerospace Engineering. He received his M.S. degrees from Politecnico di Torino in 1989. His research interests include flight mechanics, unmanned aerial vehicles and space systems. He is a Senior Member of AIAA and a Member of AHS. 